\title{
Violencia intersubjetiva y discriminación racista en la escuela: representaciones desde los maestros en Huánuco
}

Recibido: 30/09/2016

Aprobado: 07/11/2016

\author{
Pedro Jacinto Pazos \\ Universidad Nacional Mayor de San Marcos \\ $<$ jacintopazos@hotmail.com>
}

\begin{abstract}
RESUMEN
Son diversas las palabras, que se encuentran en el vocabulario de los pobladores de la región y, estas se complementan cuando explican las frases que conjugan dentro de estas expresiones discriminatorias: "No sirves para nada". "Eres un serrano", "Eres un shuco", "Cholo apestoso", "Indio cochino", "Cholo de m...", "Cholo cochino", "Serrano asqueroso". A los maestros, cuando se les enunciaban las preguntas con el temario a la mano, muchas de las palabras y las frases la describían dentro de un jolgorio, que parecían dar cuenta de un hecho que les incluía en su forma discriminatoria en la que también se veían participantes. Además, las cifras demuestran que es muy común escuchar palabras racistas entre alumnos. Lo que concuerda con todas las nominaciones que se han realizado al respecto. Y aquí, lo primero, que sale a relucir es la palabra "cholo". Pero hay que tener cuidado, porque estamos con profesores de la sierra huanuqueña donde, los indicios testimoniales ponían el sujeto "cholo" como el sentido de lo serrano o de lo andino.
\end{abstract}

Palabras clave: Intersubjetividad, discriminación, racismo, Huánuco.

\section{Intersubjective violence and racist discrimination in schools: representations from teachers in Huanuco}

\begin{abstract}
There are several words that are found in the vocabulary of the inhabitants of the region, and these are complemented when they explain the phrases that conjugate within these discriminatory expressions: "You are not good for nothing". "You are a serrano", "You are a shuco", "Cholo smelly", "Indio cochino", "Cholo de m...", "Cholo cochino", "Serrano disgusting”. Teachers, when asked questions with agenda, many of the words and phrases described in a fun, which seemed to account for a fact that included them in their discriminatory form in which also They saw participants. In addition, the figures show that it is very common to hear racist words between students. Which agrees with all the nominations that have been made about it. And here, the first thing that comes out is the word "cholo". But we must be careful, because we are with professors of the Sierra Huanuqueña where, the testimonial evidence call a person "cholo" as the sense of the Serrano or Andean.
\end{abstract}

KeYwORDs: Intersubjectivity, discrimination, racism, Huánuco. 


\section{Introducción}

$\mathbf{U}$ $\mathrm{n}$ informe narrado por los medios periodísticos, en el mes noviembre del 2006, sobre un colegio de nivel secundario de un Asentamiento Humano, al Norte de Lima, presentó un hecho categórico que nos conmovió y llevó a preocupar sobre el sentido belicoso en que se presentaban los alumnos en las escuelas de los sectores populares de la Capital ${ }^{1}$. En el lapso - y, según testimonios de los profesores - el relato implicaba los insultos, la humillación y el agravio que se ocurrían constantemente entre los adolescentes. Del sarcasmo y la burla de un grupo de escolares, frente al alumno más frágil, marginal y de condición humilde o, en extrema pobreza, -que además era un buen estudiante- se empezaron a mezclar odios, rencillas, agresiones e injurias constantes hasta que en una ocasión entre ataques y violencia un grupo de cuatro alumnos dio el puntillazo final: la muerte de uno de ellos ${ }^{2}$. No fue la única agresión de entonces. Los medios se comenzaron a poblar con esta pauta de noticias o con este tipo de violencia, que los psicólogos le llaman bullying ${ }^{3}$. Todos llamaban a combatir la violencia en la escuela. Se re-generó de este modo, la escuela para padres y de paso reuniones desde sus instancias organizativas, sin entender lo que se forjaba dentro de dicha colectividad: rencillas y aprietos que son - hasta hoy - parte de su cotidianidad. Esto conllevaba también, los ataques vertiginosos por parte de los medios de comunicación a los maestros. De hecho se pensó, que el único sujeto y partícipe directo de esto es el maestro y, el único que tenemos que poner en la picota frente a todos los sucesos que se observan en la escuela, es éste y por lo tanto, no solo culpable de los niveles educativos en la cual se desenvuelve la educación peruana sino de paso: el causante de estas desgracias entre adolescentes y nińos. En el contexto socio-político-educativo todos participan: Reforma

$1 \quad$ Logré recabar algunos testimonios de los profesores de entonces (20062007), que por razones obvias los mantengo en el anonimato.

2 Esto fue público en la prensa limeña de la época. Ver: La República 11 de noviembre del 2006.

3 El bullying o acoso escolar es una forma de maltrato psicológico, verbal o físico que se reitera constantemente. La información de los colegios públicos y privados afiliados al Sistema de reporte de casos sobre violencia escolar, SíseVe, del Ministerio de Educación, entre el 15 de setiembre de 2013 y el 30 de abril de 2016, un total de 6.300 estudiantes denunciaron ser víctimas de violencia en los colegios. Las características son: Física: 3,049, Verbal: 2760, Psicológica: 2136; Sexual: 589; Internet/celular: 226; Hurto: 126, Con armas, 53. En: http://www.siseve.pe/Seccion/DownloadPDF. Recuperado: setiembre de 2016. educativa, la carrera educativa magisterial, huelgas de maestros, exámenes autorizados desde el Ministerio de Educación, y de paso injurias e insultos de parte del gobierno de turno ${ }^{4}$. Pocos se preguntaron, ¿Qué hizo y hace posible tanta violencia y tanto conato en la escuela?" ¿Solamente en la Capital o también en las partes altas andinas del país?

Un segundo momento de observación -y testimonio según una maestra del aula-, en plena clase de alumnos del sexto grado de primaria en un colegio al Este de Lima los insultos iban y venían en pleno horario de estudios ${ }^{6}$. Los actores sociales principales, tienen los mismos rostros y podríamos decir hasta los apellidos más originarios que pueden existir en la sociedad peruana $^{7}$. De repente, de un momento a otro salían a relucir las palabras e insultos de mayor calificación que se establecían entre lo racial y racista que se pueda imaginar entre los niños de la misma condición social y cultural que podamos haber observado ${ }^{8}$ La geografía peruana sigue siendo el imaginario de distinción de rostros y "colores". Es la escuela del siglo XXI. La pregunta de entrada: ¿racismo entre los mismos ros-

$4 \quad$ Hay que observar bien las palabras y las frases que se le expresaron a los maestros por parte del presidente Alan García, y leer el periodismo de entonces. Precisamente tomamos los años en que sucedieron los hechos narrados: 2006, como precedente y su continuación actual. Las huelgas del SUTEP de entonces se sucedieron por aquellos días y lo más significativo fue la del 2007, en pleno gobierno de García: "ociosos, "burros", comechados". Hay mucha información al respecto. Ver: https:/www.youtube.com/watch?v=RyrCLS944eY.

5 En el transcurso, un movimiento de los pueblos indígenas en la Amazonía peruana, el 5 de junio de 2009, llevaba a una confrontación entre policías y nativos que llevó a la masacre y muerte de 33 pobladores entre civiles y policías, que llevaron a un enfrentamiento, producto de una movilización regional que realizaban entre otros, los pobladores Awajun y Wampis de la zona. En realidad, lo grupos nativos hacían sus reclamos por la intromisión de las grandes empresas transnacionales extractivistas en sus territorios, producto de las normas que el gobierno establecía. Entonces, salieron a relucir palabras que el vocabulario de políticos e ideólogos neoliberales profirieron, ubicando "su jerarquía y superioridad". El más resonante fue el del presidente de entonces, Alan García. (Ver: http://www.diarionorte.com/article/30220/. Recuperado: 3 nov. 2016). ¿Está la escuela lejos de todo esto? No. La naturalidad de esgrimir la superioridad es vasta desde el político que se siente con poder y los medios como redes sociales y televisión que cumplen su rol en este sentido. Solamente, quisiera que se graben estas últimas palabras propias de la discriminación eurocéntrica europea hacia el mundo indígena.

6 Se trata del Colegio Mariscal Ramón Castilla de Chaclacayo. Los alumnos tienen procedencia de los distintos asentamientos humanos, de las zonas populares. Muchos proceden de Huaycán y Horacio Zeballos. Tienen origen de padres migrantes de la Sierra Centro y Sur del Perú.

7 Expreso que los apellidos de los alumnos son en quechua, y la observación se realizó en setiembre del 2012.

8 Las palabras: "serrano feo", "serrano horrible", "cholo", "vicuña", etc. eran los más proclives. Los insultos van con su extensión coprolálica. La profesora del aula me entregó más calificativos. 
tros, los mismos grupos "étnicos" en la escuela que se supone es el espacio de los buenos modales y las buenas prácticas de comportamientos?, ¿`cuestión de los maestros, de los padres de familia o una estructura social que los domina y los encapsula en laberintos discriminatorios de todo tipo y de toda especie? Pero, ¿por qué hablar de discriminación racial y racista en el país desde la escuela, cuando ya el tema y las explicaciones parecen haber llegado a su cenit donde la propuesta, es más bien la integración social y la idea de una sociedad nacional en ciernes??

Estas preocupaciones nos llevaron a establecer cómo los principales discursos, frases y palabras explicadas y teorizadas por nuestros principales intelectuales del siglo XIX, no estaba exenta de los que en la racionalidad y la subjetividad tenían los alumnos en pleno inicios del siglo XXI, desde su sentido común ${ }^{10}$ : ¿violencia subjetiva interiorizada en los alumnos que se extiende desde los ámbitos socio-racializados bajo una desigualdad social persistente en el Perú actual? Quizás, hoy, la grosería o el insulto sea más cruento, pero no deja de llamar la atención que es entre sujetos con el mismo "color de piel" y los mismos rasgos fisiológicos los que se manifiestan en la escuela. Por lo tanto, entendemos que no es cuestión de piel: ¿¿Subjetividad, imaginarios, mentalidad, pensamiento retrocolonizado sobre el sentido de superioridad desde ciertas distinciones discriminatorias que se imponen? Las incógnitas continúan.

\section{Entre lo racial y lo no racial: algunas referencias en las ciencias sociales}

Propongo un referente teórico introductorio para entender los rasgos y características que implica entender el racismo en el país. Suzanne Oboler (1996), sostiene

9 Las investigaciones que hemos realizado y se han realizado por las ciencias sociales, tienen un signo en común es, que gran parte de los encuestados y entrevistados sostienen que no han sido discriminados en su gran mayoría. Esto nos has sucedido con microempresarios en Lima Norte, con profesores en Lima (estudiando maestría en La Cantuta y San Marcos) con alumnos en Villa el Salvador y además con consumidores en Jockey Plaza. Ver: Montoya, 2011; y Jacinto, 2014 y 2016.

10 Guillermo Rochabrún (2015), Guillermo Nugent (2014) y en sus inicios Alejandro Ortiz (1999), explican de mejor manera cómo es posible no hablar de racismo en el Perú. Desde luego de "epidermis" y de estructuras sobre las cual se levantaba el racismo hasta mediados del siglo XX en Estados Unidos o Europa, no tiene sentido de comparación, pero en lo peruano, sigue en la cabeza de los sectores populares y elitistas del país. que el período de transformaciones en el Perú es propicio para evaluar el grado a que las imágenes raciales expresadas a través de los rótulos sociales y sus atributos se correlacionan directamente con la posición de poder y de status que ocupan los distintos grupos en la sociedad. La ambivalencia en las actitudes hacia los chinos y cholos, por ejemplo, señalan, por una parte, sus respectivas historias, enraizadas en una jerarquía estamental y reforzada por imágenes tradicionalmente negativas que se les ha atribuido y, por otra, apuntan al proceso a través del cual estas imágenes parecen estar cambiando hoy, a través de la creciente visibilidad de los cholos y los chinos en el espacio público nacional ${ }^{11}$. En sí Oboler, trata de discutir el racismo desde una lógica comparativa entre lo que se observa en el Perú, Lima más específicamente y lo que ve en Estados Unidos. Sus sujetos de estudios son un grupo de estudiantes de Derecho que bajo entrevistas a profundidad entablan el tema. Dos categorías se le presentan en su trabajo: las leyes y las costumbres. Esta última idea, como el referente que se impone en los estadounidenses donde la racialización y el racismo es muy a "color de piel", y parte de la costumbre o de la vida cotidiana y del poder, donde el empresario, profesional o ciudadano de clase media negro, Latino o, latinoamericano, tiene bien marcado su "rótulo étnico", y por lo tanto, por más ciudadano que sea conforme se le dio por ley, no quiere decir que la costumbre de racializar desde las instituciones policiales no le dejen de mirar como el "otro", el peligroso o el delincuente. Mejor decir, la ley de la ciudadanía no funciona, así lo hayas conseguido. Y esto no lo ubica para el caso peruano. Aquí más bien, y según su versión empírica el "racismo es solapado" y lo ubica en un espacio ambivalente donde la clase social y el estatus se hace presente con más tesón. En realidad, lo que trata de explicar, es ver el racismo, no en términos estadounidenses, como se hace en el Perú, desde las ciencias sociales y desde el sentido común. Una comparación de este tipo no le suena coherente, y menos con los judíos, donde el antisemitismo no tiene signos de comparación. Desde luego, son historias, procesos y estructuras distintas, pero de alguna manera, las formas en que se ha expresado en países con historias diferentes implica mirarse en el espejo de quien lo ejerce y de quien se presenta como sentidos subjetivos coloniales y alienantes que no podemos decir que si bien los estadounidenses lo tienen por costumbre,

11 Ver: Oboler, 1996 
nosotros lo tenemos porque nos han puesto en el inconsciente que el logro del blanqueamiento conlleva status y poder. Para esta autora:

Al fin y al cabo, el racismo es una ideología que ha plagado al mundo moderno, especialmente en el siglo XX. Es una ideología que busca y refuerza manifestaciones de diferencias biológicas y visuales para justificar las desigualdades socioeconómicas. En este sentido, la raza, así como la práctica de discriminación racial, no es ni una categoría de la naturaleza ni un dato natural, sino exclusivamente una construcción social. Siguiendo esta definición, el racismo es sobre todo una prueba contundente del éxito de un artificio construido socialmente y enraizado en las prácticas ideológicas que durante los siglos XIX y XX justificaron la esclavitud, la dominación y la discriminación de un grupo por otro. (Oboler, 1996: 27)

Desde luego, se puede construir un imaginario social que se obtiene desde las relaciones sociales visibles, que implican el concepto de raza como ideología y poder. Es decir, el color y la especie. No obstante, son las desigualdades sociales y económicas las que hacen del individuo y las personas consagrar una idea que implica el mismo predominio "étnico" y "racial" inexistente desde su forma natural. En el fondo, querer ubicar una distinción desde lo social, por la búsqueda del poder donde lo único que le queda al actor social es dicha desigualdad social para lograr primar un estatus económico que pueda supeditar al sujeto en tanto "sin poder étnico-racial” pero sí con distinción social y económica que lo haga "otro" de jerarquía superior. Es la búsqueda de un escalafón epidérmico, no obstante, bajo la subjetividad colonizada de una sociedad que lo trata de sacar a relucir en espacios supuestamente homogéneos. Quizás en el fondo,-siguiendo a Oboler- la cuestión de raza y poder se remite fundamentalmente al conflicto racial tal como es vivido en el cotidiano; es decir, con toda la rotulación mutua que jerarquiza cada grupo, y lo traduce a la esfera del poder. Más cuando, desde lo político debe haber un verdadero "peruano aceptable", quién puede representar de manera verídica la identidad nacional e individual, los intereses de la ciudadanía limeña y eventualmente peruana ${ }^{12}$.

Otra de las investigaciones realizadas, la ubicamos en Planas y Valdivia (2009), quienes tomando como

12 El texto alude al contexto de la candidatura y triunfo a la presidencia de la República de Alberto Fujimori. Ver: Suzanne Oboler (1996). referencia Lima, Cusco Urbano y Cusco Rural, dejan en claro que 'raza' es un motivo importante de discriminación para sus informantes en las tres localidades, que investiga, pero que su relevancia relativa y la manera en la que se articula con otros motivos de discriminación varía según la localidad de estudio y los lugares de ocurrencia ${ }^{13}$. Desde esta percepción, la 'raza' como motivo de discriminación se relaciona frecuentemente con otros ejes de diferenciación social (clase social, ingresos, etnia, lugar de nacimiento, apellido, nivel de escolaridad, idioma o forma de hablar, etc.). En este sentido, los resultados del estudio, de estos autores, plantean que la mecánica de la discriminación 'racial' supone una articulación de la 'raza' con esas otras dimensiones o motivos, y que esta articulación es diferente en cada localidad. Explican:

Cabe señalar también que los motivos en las tres localidades no se vinculan entre sí de la misma manera. Por ejemplo, la 'raza' en Cusco rural se interseca con procedencia y forma de vestir; en Cusco urbano, 'raza' se vincula también con forma de vestir, pero además con nivel socioeconómico y vara o coima; y en Lima 'raza' presenta una alta densidad, dado que se vincula con procedencia, apariencia física, costumbres, idioma o forma de hablar, y nivel socioeconómico. (Planas y Valdivia, 2009: 32)

De este modo, los autores manifiestan que, si consideran las forma de vestir, idioma o forma de hablar y nivel educativo como motivos culturales, se podría decir que en Cusco rural las diferencias socioeconómicas y culturales son más relevantes que las diferencias 'raciales' para explicar eventos de discriminación. Mientras en el Cusco urbano, si se comparan los motivos socioeconómicos, culturales (forma de vestir e idioma o forma de hablar) y 'raciales', se observa, una figura similar a la de Cusco rural, con la diferencia que nivel educativo no se incluye como un motivo cultural relevante y que procedencia ni es relevante ni articula el conjunto de motivos. Según sus informantes, en Cusco urbano, las diferencias 'raciales' son también menos relevantes que las diferencias socioeconómicas y culturales para explicar eventos de discriminación. En cambio en Lima, a diferencia de Cusco rural y Urbano, 'raza' es el motivo más

13 Dicen los autores: "El presente estudio ha buscado avanzar en la comprensión de esa perspectiva émica buscando mapear cómo nuestros informantes articulan el campo semántico-pragmático de la discriminación. Analizando 199 relatos de discriminación recogidos en 13 grupos focales, el documento describe cómo informantes de sectores populares en Lima, Cusco urbano y Cusco rural”. (p. 40) 
frecuente y denso, y por lo tanto el más relevante, incluso más relevante que las diferencias culturales. Un hallazgo importante de dicho estudio es que según la percepción de éstos, la 'raza' no es siempre el motivo más relevante para explicar la discriminación en las tres localidades: en Cusco urbano y Cusco rural su relevancia resulta ser menor que otros motivos sociales y culturales $^{14}$. Algo que nos llama a discutir, es el espacio geográfico, en que se manifiestan los sucesos. Siempre pensamos en las partes altas del país o de paso en la $\mathrm{Ca}$ pital o las provincias, ya con proceso de urbanización en condiciones de modernización acelerada.

Sin embargo, otra de las investigaciones que revelan importancia del tema, es la de Marisol de la Cadena (2004), que en realidad nos lleva a recorrer, desde la etnohistoria pasando por la etnografía y la antropología, rigiéndose bajo un minucioso trabajo de campo y documentado, la forma en que la raza articula la formación social peruana de los pies a la cabeza y, "cómo el racismo ha recorrido el pais, desde las universidades en las que se lucha 'por el pueblo', hasta los mercados, que son del pueblo"15. Un estudio, que se centra en la etnografía de las fiestas patronales pero que logra su recorrido a los "mercados" donde fluye el sentido cultural de la racialización de la población. Entre una población de la "elite cusqueña" y una población "india" que se desindigeniza por la misma cultura. En el tapete, la desindianización, pero alcanzado bajo un mestizaje que no deja o abandona sus ancestros culturales y más bien reafirma sus patrones originarios que bien pueden ser mirados como "caducos" y tradicionales, como lo refieren los conservadores desde los más antiguos hasta los actuales ${ }^{16}$. Escribe:

Una maestra de escuela, también mayordoma del Corpus, admitió que se sentía superior a las mestizas del mercado porque "había estudiado en la universidad y esas mujeres con las justas tienen la primaria". Ser "mestizo, pero no cholo" significa haberse despojado de cualquier atribuible origen indígena y poseer en su lugar maneras no-indígenas normalmente adquiridas por nacimiento y siempre reforzadas por algún tipo de educación más allá de la escuela secundaria. "Mestizo" tal y como este grupo lo utiliza, apela a modernas nociones de mezcla racial entre lo

14 Ver: María Elena Planas y Néstor Valdivia (2009). Discriminación y racismo en el Perú: un estudio sobre modalidades, motivos y lugares de discriminación en Lima y Cusco. Lima: Grade.

15 Excelente resumen de la contratapa del libro de M. De la Cadena (2004). Ver bibliografía.

16 Una fuerte crítica al racismo de Vargas Llosa. Ver bibliografía. indígena y lo criollo y a la supuesta evolución bicultural hacia un tipo racial superior. "Cholo" se refiere a las mujeres indígenas del mercado y a sus acompañantes, esos "mestizos sin refinar, esos indios urbanos que hablan tanto quechua como español y muchas veces más quechua", como Gloria (la propietaria de la cafetería) aclaró con dureza mientras afirmaba su propia ignorancia de esa lengua (De la Cadena, 2004: 283)

El racismo resulta así socialmente legitimado, puesto que formaría parte de una cultura hegemónica, de la que participan los de arriba y los de abajo ${ }^{17}$. En realidad, de lo que se trataba era de explicar cómo las distinciones y jerarquías se establecían a nivel de lo "indio" y de los "mestizos" o cómo los indios eran percibidos o se autopercibían como mestizos desde lo urbano. La desindianización, tal como fue explicada por los cuzqueños indígenas significa despojarse de los marcadores que evidencian la condición social de indianidad así como andar descalzos o con ojotas en otras palabras "desindianizarse significa progresar", es por eso que los cusqueños indígenas de la clase trabajadora emplean el término mestizo para identificar a la gente alfabetizada y económicamente exitosa ${ }^{18}$. Por su lado, Rochabrún (2014), invita a abandonar la palabra racismo, sin dejar de lado, la idea de discriminación:

Mi impresión, una vez más, es que todo estaría más claro si 1) se abandona la palabra 'racismo' - no tiene ningún significado preciso, ni remite a ninguna estructura ni a ningún mecanismo definido, aunque cada vez que es pronunciada parece como si lo tuviera- y 2) si hablásemos simplemente de discriminación; una sociedad profundamente estamental aunque carezca ahora de estamentos definidos, donde está claro es lo que debe ser discriminado, pero donde lo discriminante queda borroso o vacío. (Rochabrún: 2014, 28)

En realidad, es precisamente atreverse de cómo una estructura resulta incólume desde la racionalidd de la gente o de una población que ha sido enajenado desde su intersubjetividad. Es decir, una colonialidad simbólica que ha quedada impregnada hasta el día de hoy. Y, uno de los principales autores, que recorre la idea de intersubejtividad desde la colonialidad y su descolonialidad res-

17 Rochabrún (2014), invita a abandonar la palabra racismo, sin dejar de lado, la idea de discriminación. Ver Bibliografía.

18 Ver: Marisol de la Cadena (2004). Indigenas mestizos. Raza y cultura en el Cusco. Lima: IEP. 
pectiva es Anibal Quijano (1993) quien explica, cómo la idea colonialista de raza y racismo, quedó impregnada en la subjetividad de la gente, y cómo su práctica social, de alguna manera lo identifica con estas formas de relación social de dominación. Por supuesto, una de las ideas que suscribimos, y tratamos de orientar desde su lado empírico ${ }^{19}$. En uno de sus textos escribe:

La idea de raza ha sido practicada tan consistentemente durante más de 500 ańos, que todo el mundo, yo diría el $99 \%$ de la población de la especie, ha terminado siendo educada en esta misma perspectiva, y lo que corresponde a la historia del poder ha sido admitido como parte de la historia de la naturaleza; lo que pertenece a la materialidad de las relaciones sociales ha sido admitido como parte de la materialidad de las personas mismas. No se puede, en consecuencia, llevar a la práctica las promesas de la modernidad sin la destrucción de la colonialidad, es decir sin la descolonialidad del poder. (Quijano, 2012: 29-30)

Desde luego, la idea de raza se asume desde la vida cotidiana en su sentido histórico producto de la fuerza y la imposición de quienes logran regentar un sistema y una sociedad. El país esta inserto en este mundo donde la colonialidad de la subjetividad y del pensamiento rigen las acciones de las personas. Es, desde esta perspectiva, que tenemos que observar la discriminación que conlleva las formas de racialización en la sociedad peruana. En realidad, el concepto de racismo implica varias acepciones que se complementan, no puede estar desligada de las relaciones de poder y la noción histórica colonialista sobre la cual se construye. Los orígenes de quienes erigieron en la racionalidad de la sociedad peruana un sentido de distinción tiene sus antecedentes en la colonialidad de la subjetividad simbólica del país. Lo que se observa más nitidamente en la política y en los estudiantes universitarios, asi como, en los distintos espacios en los que nos movilizamos, las festividades religiosas o, los mercados como se observó en los estudios anteriores, bien podemos decir los vemos en los distintos espacios de la sociedad peruana. Una de ellas: la escuela. Quijano explicaría:

La producción de la idea de "raza" y la "racialización" de las relaciones sociales da lugar a una nue-

19 Ver: Quijano, A. (1993). Raza, etnia y nación en Mariátegui. En: José Carlos Mariátegui y Europa. El otro aspecto del descubrimiento. Lima: Editora Amauta. pp. 167 - 189. va perspectiva intersubjetiva, que impregna todos y cada una de los ámbitos de la existencia social, y que oriente, define, legitima, las nuevas relaciones coloniales, en su materialidad y en su intersubjetividad, en el mismo movimiento histórico en el cual va emergiendo Europa Occidental como sede del control central del nuevo patrón de poder. Esto es, en el mismo proceso de eurocentramiento del nuevo poder cuya base fundacional es la racialización de las relaciones en la nueva existencia social bajo el dominio colonial ibérico. (Quijano, 2009: 40-41).

Es esta intersubjetividad latente la que tratamos de investigar y trabajar desde la idea de raza y racismo. No podemos estructurar socialmente una categoría social que presente sus modalidades epidérmicas, pero sí podemos adentrarnos en las mentalidades y los imaginarios que recorren un hecho concreto y sus repercusiones en el mundo de la vida y del trabajo, en sus distintas manifestaciones relacionales. En sí, la colonialidad simbólica que recorre las subjetividad peruana.

\section{Métodos para explicar la discriminación racial}

Los métodos utilizados en esta investigación son el deductivo-inductivo o viceversa. Logramos un análisis comparativo cualitativo y cuantitativo desde los resultados de las encuestas y, las entrevistas a modo de testimonios, aplicadas durante la acción empírica. Es esencialmente exploratorio. En un primer momento, iniciamos el trabajo de campo, con un cuestionario abierto que enlazaban la temática con sus respectivas categorías. Las ideas centrales sobre la subjetividad racial y la discriminación racista desde sus sentidos y significados que expresan los alumnos en el salón de clases o en el colegio, desde la percepción de los profesores. Se realizó en la misma ciudad de Huánuco ${ }^{20}$. Tomanos

20 Huánuco se caracteriza por su excelente clima, su variada geografía y su ingente riqueza en recursos naturales, destacándose su capacidad hídrica y forestal. Se encuentra ubicado en la zona centro oriental del país, contando con una superficie de $36850 \mathrm{~km}^{2}$, equivalente al 2,9 por ciento del territorio nacional. Se distinguen dos macroregiones naturales, la sierra con $22012 \mathrm{~km}^{2}$ y la selva con $14837 \mathrm{~km}^{2}$. Su diversidad geográfica es de tal magnitud que permite albergar a 7 de las 8 regiones naturales clasificadas por el Dr. Pulgar Vidal. La agricultura constituye la principal actividad económica de la población huanuqueńa, al concentrar casi el cincuenta por ciento del empleo en la región. Sin embargo la productividad de la mano de obra aún se encuentra rezagada respecto al promedio nacional, debido principalmente al bajo nivel de capitalización del sector. Así, solo el 7 por ciento de superficie agrícola cuenta con riego asistido, en tanto que menos del 1 por ciento de las unidades agropecuarias emplea energía (eléctrica y/o mecánica) en sus labores frente a un 10 por ciento en 
como referente principal, a los alumnos (maestrandos) del posgrado de la maestria en Educación de la mención Docencia superior e Investigación que realizaban el curso Educación y Cultura, bajo mi responsabilidad en la Universidad de Huánuco ${ }^{21}$. Aquí realizamos 27 entrevistas abiertas - a modo de testimonio- cuyas respuestas tomamos como el soporte material empirico para la construcción del cuestionario a aplicar como encuesta a los maestros de la ciudad y que aplicamos posteriormente.

Es desde este material, que en un segundo momento, a modo de consolidado referencial, ubicamos a los maestros que realizaban su capacitación profesional, por parte del Gobierno Regional, en la Universidad Hermilio Valdizán de Huánuco, donde aplicamos de manera aleatoria una encuesta a 78 maestros. He trabajado la encuesta en su conjunto con las respuestas primigenias del primer grupo (de la Universidad de Huánuco), cuyo carácter era completamente libre y abierto. El estudio desarrolló un análisis transversal, que corresponde a un momento de tiempo, en busca de nuevos conceptos que hagan posible la comprensión de los problemas álgidos de la educación peruana. Todo el trabajo de campo fue realizado en las dos universidades principales de la ciudad de Huánuco. Por lo tanto, para nuestros casos en estudio contamos con ambas etapas. ${ }^{22}$

En el presente artículo, realizaremos un análisis cualitativo de lo que expresaron, los maestros, de manera abierta y testimonial. Luego, observaremos en base a las estadísticas arrojadas, las expresiones comparativas que ellas denotan desde lo testimonial.

\section{La subjetividad desde los maestros}

Esta primera parte refiere los resultados del cuestionario abierto que solucionaron los maestros desde sus concepciones y percepciones que asumen como

promedio en las demás regiones. (Recuperado, 2 de noviembre de 2016. En: http://www.bcrp.gob.pe/docs/Proyeccion-Institucional/ Encuentros-Regionales/2015/huanuco/ies-huanuco-2015.pdf)

21 En realidad, una Universidad Particular regentada por un Comité Patronal y por su Asamblea y Consejo Universitario en Huánuco. El curso que dicté en dicha Universidad era sobre Educación y Cultura.

22 En los instrumentos de investigación realicé un cuestionario abierto a los 27 maestros en las cuales describían sus percepciones sobre la discriminación. Gran parte de los testimonios se discutían en el aula, de tal forma que muchas de las palabras y frases se asumían de forma natural y a veces, bajo la sorna y el sarcasmo se podía establecer una interrelación de mutuo conocimiento de lo que se describía. También utilicé una encuesta estructurada y estandarizada que contenía preguntas cerradas y de escala. Esto lo realicé en pleno trabajo de campo, aprovechando la capacitación de los maestros en la UNHEVAL. docentes en el aula frente a los alumnos. La subjetividad, debemos entenderla, como la inter-relación de la producción de significados que le dan sentido a la acción comunicativa, entre individuos que interiorizan espacios sociales y culturales. Esto, está entrecruzado, por una serie de factores históricos que implican dicha interacción, donde las ideas de poder y de dominación es una constante, entre los sujetos sociales que la asumen, no sin antes entender la estructura social que le da sentido. ${ }^{23}$

\section{Referencias generales de los sujetos sociales en investigación}

En esta parte tocamos los datos generales de los entrevistados con cuestionario abierto testimonial y los de cuestionario estructurado desde la encuesta realizada ${ }^{24}$. Los profesores entrevistados, son en su gran mayoría de la misma ciudad y el resto son de las provincias de Huánuco y de provincias aledańas ${ }^{25}$. El grueso de todos ellos se encuentra en la edad promedio de los maestros, entre 25 y 40 ańos de edad. Esto indica, que existe una nueva generación, que se están encargando de la educación de los niños y adolescentes, ya desde inicios del nuevo siglo. Como se conoce, gran parte de los profesores que venían ejerciendo sus labores en esta actividad han sido despedidos o cesados unilateralmente de tal forma que los cambios en el sector educación se vienen realizando de manera drástica ${ }^{26}$. Las nuevas generaciones de maestros, son los que estudian posgrado en cualquiera de sus niveles por lo que se encuentran en plena capacitación, como obligación

23 En realidad elaboro las propuestas que Quijano (1993, 2005) y Bourdieu (1995) venían trabajando teóricamente para su explicación, desde una lógica etnográfica.

24 Ver la sección de métodos e instrumentos realizados.

25 "Según los resultados del Censo del 2007 en el departamento de Huánuco existen 79 mil 241 personas de 15 y más años de edad que no saben leer ni escribir, lo que equivale al $16,6 \%$ de la población de este grupo de edad. Comparado con el nivel de analfabetismo de 1993, se redujo en 8,1 puntos porcentuales. En términos absolutos la población analfabeta ha disminuido en 10 mil 686 personas". En: Inei, 2007. Recuperado en octubre del 2016: http://proyectos.inei.gob.pe/web/ biblioineipub/bancopub/Est/Lib0838/libro20/cap02.pdf

26 Se dice de acuerdo a las versiones de los mismos profesores que se han despedido o cesado más de ocho mil profesores que venían ejerciendo la docencia en más de veinte años. Se le puso como pretexto su "nombramiento interino" sin contar formas de reinsertarlos desde sus capacidades en el aula. Entre ellos también se han logrado cesar a los de más de 65 años que ya se puede decir que resta una generación, que además, es muy mínima para hacer el recambio generacional de lo que pide el Banco Mundial y tenga a su merced el poder ideológico y sistemático en el sector. 
a los concursos y permanencia que requiere el régimen educativo actual. En realidad, estos cambios implican todo un sistema, que confronta a las organizaciones de maestros que se oponen a la reforma educativa neoliberal. Como son los del Sutep-Conare, que desde los distintos ámbitos regionales aún persiste contra la privatización de la educación, y el Sutep-oficial-Lima que es dirigido por los partidarios de Patria Roja, y que la mejor manera de desarticularlos es haber sido acogidos por los distintos gobiernos en el Ministerio de Educación, desde inicios de siglo. Por lo tanto, la exclusión y extinción, o la acogida oficial, de estas organizaciones ha logrado imponer una política educativa desde los designios del mercado ${ }^{27}$. Una de las medidas, son los concursos públicos "meritocráticos" que de alguna manera conlleva selección y por ende despido. Pero, lo curioso, viene cuando se contratan a los mismos despedidos, que precisamente se despidieron por mediocres o "anti-meritocráticos".

Podemos referir que el grupo en la presente investigación, se les distingue solo por encontrarse en espacios de estudios diversos, como son los profesores que entonces estudiaban en la universidad privada o en la pública. Pero todos, en el momento de la encuesta respondían a su profesión de educadores. Algunos querían diferenciarse por sus especialidades, sin embargo, todos eran parte de la docencia. En las entrevistas abiertas, hemos elegido al azar varones, sin embargo lo que se observa en la encuesta, es que existe una mayoría relativa de entrevistadas mujeres, mientras que el sexo masculino está un poco por debajo. De hecho en esta parte del Perú tenemos un fragmento mínimo de los maestros que hablan quechua y aymara, mientras que la gran mayoría son de habla castellano. Los profesores de acuerdo a la versión que manifestaban muchos de ellos tienen su centro de labores en las alturas de la región, por lo que no es casual que se expliquen de centros educativos muy lejanos a la ciudad. Aquí, las escuelas se encuentran muy entremezcladas, desde las que se ubican en las alturas serranas de la región hasta los que se tienen en la misma ciudad.

El profesor-biólogo era parte del grupo de maestros y también respondió las preguntas que casi en nada diferían del resto. Se asumió al azar del grupo de testimonios.

27 Versión recogida de la voz de los maestros que se organizan desde el Sutep-Conare-Lima. (También ver: web Conare-Lima).

\section{Escuela y respeto}

Son estos dos conceptos lo que propusimos como parte del ejercicio que se puede observar al interior de dichas instituciones donde labora el maestro. Estas ideas son propias de la continuidad de generaciones pasadas que se preguntan si el respeto que ellos vivieron en la escuela es la que existe actualmente o pervive de alguna manera. Hay que entender el respeto, como la construcción de un valor social, sobre la cual se erige la convivencia entre los seres humanos donde lo étnico, lo social y lo cultural es parte de una sentido relacional de los individuos y las sociedades, desde su sentido horizontal. En el fondo, es comprender, que el respeto que se tenía hacia los padres hace dos o tres generaciones atrás es completamente disímil a lo que observamos actualmente. Por ende, comprender, que el respeto en la escuela entre alumnos y profesores tenía un sentido de coerción o coacción donde el sentido vertical de la relación se asumía, más que de forma obligatoria, por deber y reconocimiento a la "mayoría de edad". En el fondo, un valor fundamental que implicaba, el saludo cordial diario y de entrada, lo que implicaba un significado de la tolerancia. Es lo que en parte, evocan las viejas generaciones de profesores y padres de familia en la escuela actual. Entonces: ¿Cómo se pueden ubicar estas ideas desde la percepción de los maestros actuales y cuánto de actualidad tienen? Hicimos un recorrido a partir del ejercicio de entrevistas y cuestionarios a profesores de educación básica, para explicarnos cómo funcionaban estas frases y palabras tan complejas de poder asimilar y cómo se describen entre los alumnos o los maestros mismos. Tuvimos en cuenta la relación escuela y respeto, para explicarnos lo que tanto inculca el Ministerio de Educación o la consigna que permanentemente se manifiesta por parte de los mismos como sentido de horizontalidad.

Como se observa desde los resultados, existe una apreciación sensata acerca de la escuela, pero no pocos, manifiestan su disconformidad con la idea del respeto y la tolerancia que dentro de la escuela debe primar. Es decir, en esta parte, se explica cómo la escuela va perdiendo el espacio de ser una institución intra-inter-cultural, por no decir tolerante y respetuosa en sus actos y conductas. Lo que sale a relucir en gran parte de las respuestas de los entrevistados, es una práctica de antivalores, una falta de comunicación y, de una no moral o inmoralidad en la práctica, donde los maestros y alumnos no enseñan con el ejemplo. Por lo tanto, 
TABLA 1: DATOS GENERALES DE LOS MAESTROS ENTREVISTADOS / TESTIMONIOS*

\begin{tabular}{|c|c|c|c|c|c|c|}
\hline Nombre & Edad & Estado Civil & 0cupación & Institución Educativa & Idioma & Religión \\
\hline 1. Alejandro Duran & 58 & Casado & Doc-Biólogo ${ }^{* *}$ & Universidad de Huánuco & Castellano & Católica \\
\hline 2. Omar Quispe & 24 & Soltero & Docente & I.E. Leoncio Prado & Castellano & Católica \\
\hline 3. Stiven Ibarra. & 27 & Soltero & Docente & C.N. UNHEVAL & Castellano & Católica \\
\hline 4. Javier Portugal & 29 & Soltero & Doc-Historia & I.E. Secundaria & Castellano & Catol-Prot \\
\hline 5. Max Huárac & 48 & Soltero & Doc-Educador & I.E. Parr. Padre Abad. Tingo María & Castellano & Católica \\
\hline 6. Aníbal Poma & 35 & Conviviente & Doc-Fis-Mat & I.E. Daniel A. Carrión, Pasco & Castellano & Católica \\
\hline
\end{tabular}

ponemos como supuesto, que el respeto ha perdido vigencia. Quizás, lo que aquí se quiere advertir es la decadencia de la escuela desde sus actores sociales donde los "antivalores" van de la mano de los medios de comunicación. O, donde las causas, se endilguen a los padres de familia, por una falta de trabajo educativo con éstos. Algo que se insiste demasiado, desde sus percepciones, es ubicar los orígenes familiares entre los alumnos, como signo de distinción, de clase y de "raza", que hace explicarnos la escuela bajo un sentido a-funcional, si asumimos dicha premisa. Esto se une a las fuertes discrepancias que existen al interior de los mismos docentes, donde los líos internos salen a relucir desde sus propios testimonios. En el fondo, una disputa constante que se trata de explicar en estas referencias. Si bien, el objetivo central, de la educación es la tolerancia y la búsqueda de una socialización intercultural justa y equitativa desde el conocimiento, lo que establecen los resultados de los entrevistados, es que prima una intervención inter-subjetiva que pasa por el conflicto y, una violencia simbólica constante. Esto se observa en primacía, cuando los maestros entrevistados, hacen distinguir la desestructuración del sentido institucional de la escuela bajo sus principales actores sociales. Y, sobre todo, ellos desde los protagonistas, que la integran: profesor-director; directorpadres de familia; profesor-profesor. Además de una interrelación permanente con los alumnos, donde los padres de familia juegan un papel fundamental. En gran parte de los casos, no se pueden aparentar las fuertes pugnas existentes actualmente. Entonces, si bien los entrevistados explican que, la escuela es un lugar donde se recibe educación, o donde se imparte valores o donde se aprende conocimientos, una de las propuestas que rigen esta visión es que se ha perdido lo fundamental del trabajo escolar.

\section{Palabras y frases de discriminación entre los alumnos}

De lo expresado anteriormente, se puede colegir cómo se enuncia todo esto, entre los alumnos o entre los profesores. Según las versiones recogidas tenemos que las palabras que se observan entre los adolescentes son: "Serranito", "selvático", "shuquito". "Serrano", "shuco", "negro", "hueco", "colorado", "chuncho", "cholo", "opilado", "pisco", "gringasho", etc. -"Narizón”, "panzón", "calavera", "chato", "cuatro ojos", "negro", "sobón”. "Fuera limeño de M.”. "Ese es un negro asqueroso". "Fuera sucho" (alumno de baja estatura). "No seas chuncho", "déjate jugar por feo", "fuera bruja”. "Chato", "zonzo", "tarado", "burro", "idiota", "negro". "Enano", “estanciero", "chaparro", etc. Y las formas de discriminación que se establecen entre ellos se dice: "Por el vestir", "por la calidad de útiles", "por la economía de padres", "por el cargo político de padres". O también, como resume uno de los maestros: "Porque sus padres son pobres" o "porque es un mugriento pobre".

Desde luego, entre alumnos, se entremezclan insultos, agresiones verbales, agravios, ofensas y de hecho cuestiones que salen a relucir tan subjetivamente en las distintas formas de discriminación. No podemos describir netamente lo que puede ser una búsqueda del color de la piel o la epidermis, sin antes entender cómo se expresan los distintos momentos de injuria y de vilipendio. Es que las alocuciones, en el momento de expresarlos conllevan el ánimo del sujeto y la relación que obliga a sus dicciones. En la mayoría de los casos 
TABLA 2: ESCUELA, RESPETO Y TOLERANCIA

\begin{tabular}{|c|c|c|c|}
\hline MAESTROS & ESCUELA & LA ESCUELA Y EL RESPETO & RESPETO PROFESORES - ALUMNOS. \\
\hline $\begin{array}{l}\text { 1. Alejandro Duran Nieves. } \\
\text { (58). Docente. UDH. }\end{array}$ & Lugar donde se recibe educación. & Genera valores entre sus miembros. & $\begin{array}{l}\text { - No hay respeto por discrepancias: profesores - } \\
\text { director. } \\
\text { - Alumnos perciben la falta de respeto. }\end{array}$ \\
\hline $\begin{array}{l}\text { 2. Omar Quispe. (24). Docente. } \\
\text { I.E. Leoncio Prado. }\end{array}$ & $\begin{array}{l}\text { Lugar dode adquirimos } \\
\text { conocimiento y moral. }\end{array}$ & $\begin{array}{l}\text { Ha dejado de lado la moral, no obstante ser } \\
\text { intercultural e intrafamiliar. }\end{array}$ & $\begin{array}{l}\text { - Si hay respeto profesor - director. } \\
\text { - Dificultades entre docente y alumnos debido a la } \\
\text { falta de trabajo con padres. } \\
\text { - Alumno - alumno, es difíil por el origen de } \\
\text { familias diferentes. }\end{array}$ \\
\hline $\begin{array}{l}\text { 3. Stiven Ibarra. (27). Docente. } \\
\text { C.N. UNHEVAL }\end{array}$ & Lugar para recibir educación. & $\begin{array}{l}\text { Profesores y estudiantes no enseñan con el } \\
\text { ejemplo. No hay práctica de valores. }\end{array}$ & $\begin{array}{l}\text { - El profesor se pelea con el director } \\
\text { - El director se pelea con los padres. } \\
\text { - Mucha corrupción. } \\
\text { - Estudiante se ve en un caos. }\end{array}$ \\
\hline $\begin{array}{l}\text { 4. Javier Portugal (29). } \\
\text { Docente. Secundaria. }\end{array}$ & $\begin{array}{l}\text { Lugar donde el educando } \\
\text { aprende conocimientos en el } \\
\text { campo intelectual, actitudinal y } \\
\text { de valores. }\end{array}$ & $\begin{array}{l}\text { La escuela genera respeto entre sus miembros. } \\
\text { Pero, los medios, la tv. Genera violencia, } \\
\text { corrupción, matanzas, etc. que perturba el } \\
\text { objetivo. }\end{array}$ & $\begin{array}{l}\text { - La falta de comunicación y dialogo entre sus pares } \\
\text { es la principal causa de que el respeto no se aplique } \\
\text { a la realidad. }\end{array}$ \\
\hline $\begin{array}{l}\text { 5. Max Huárac (48). Docente. } \\
\text { I.E. Parroquial Padre Abad. } \\
\text { Tingo María. }\end{array}$ & $\begin{array}{l}\text { Espacio que alberga a todos } \\
\text { los componentes del sistema } \\
\text { educativo. }\end{array}$ & $\begin{array}{l}\text { Genera respeto pero se dan siempre algunos } \\
\text { antivalores. }\end{array}$ & $\begin{array}{l}\text { - "Se cultiva el respeto, con alguna fricciones que es } \\
\text { común presentarse". }\end{array}$ \\
\hline $\begin{array}{l}\text { 6. Aníbal Poma (35). Docente. } \\
\text { I.E. Daniel A. Carrión, Pasco. }\end{array}$ & $\begin{array}{l}\text { Espacio donde se imparte } \\
\text { conocimiento, aprendizaje, } \\
\text { cultura, etc. }\end{array}$ & Respeto a través de una buena comunicación. & $\begin{array}{l}\text { - Existe el principio de respeto y tolerancia entre la } \\
\text { comunidad educativa. }\end{array}$ \\
\hline
\end{tabular}

Fuente: Trabajo de campo- cuestionario a profesores. Junio, 2013. Elaboración: Propia.

debemos tener presente, el momento y sus relaciones causales o sus "decires" tan cotidianos para explicarnos conflictos o apremios que hacen de los sujetos momentos tan cruciales de la vida diaria de la escuela. Esto nos hace observar, lo que se dicen a manera de desprecio: "serranito" y "chuquito" "Limeño de m..." y "chuncho". Son locuciones donde prima lo racial-geográfico. Y percepciones que orientan orígenes y de paso rostros.

TABLA 3. DISCRIMINACION ENTRE ALUMNOS Y PROFESORES

\begin{tabular}{|c|c|c|c|}
\hline & $\begin{array}{l}\text { PALABRAS DISCRIMINATORIAS ENTRE LOS } \\
\text { ALUMNOS. }\end{array}$ & DISCRIMINACIÓN: ALUMNO - ALUMNO & $\begin{array}{l}\text { DISCRIMINACIÓN: PROFESOR - } \\
\text { ALUMNO }\end{array}$ \\
\hline $\begin{array}{l}\text { 1. Alejandro Duran Nieves (58). } \\
\text { Docente. UDH. }\end{array}$ & - "Serranito, selvático, shuquito". & $\begin{array}{l}\text { - "Por el vestir, por la calidad de útiles, por la } \\
\text { economía de padres, por el cargo político de } \\
\text { padres". }\end{array}$ & - No ha escuchado. \\
\hline $\begin{array}{l}\text { 2. Omar Quispe (24). Docente. I.E. } \\
\text { Leoncio Prado. }\end{array}$ & $\begin{array}{l}\text {-"Serrano, shuco, negro, hueco, colorado, } \\
\text { chuncho, cholo, opilado, pisco, gringasho", etc. }\end{array}$ & $\begin{array}{l}\text { - "Por el quechua, por tener objetos } \\
\text { electrónicos". }\end{array}$ & - No ha escuchado. \\
\hline $\begin{array}{l}\text { 3. Stiven Ibarra (27). Docente. C.N. } \\
\text { UNHEVAL }\end{array}$ & $\begin{array}{l}\text {-“Narizón, panzón, calavera, chato, cuatro } \\
\text { ojos, negro, sobón". }\end{array}$ & - "Por el vestir, la cara, el color, tamaño, notas". & $\begin{array}{l}\text { - "Animal, burro, bueno para } \\
\text { nada, toda la vida serás así, } \\
\text { cabeza hueca". }\end{array}$ \\
\hline $\begin{array}{l}\text { 4. Javier Portugal (29). Docente. } \\
\text { Secundaria. }\end{array}$ & $\begin{array}{l}\text { - "Fuera limeño de M."." "Ese es un negro } \\
\text { asqueroso.".Fuera sucho" (alumno de baja } \\
\text { estatura). "No seas chuncho", "déjate jugar por } \\
\text { feo"," "fuera bruja". }\end{array}$ & $\begin{array}{l}\text {-"Porque sus padres son pobres","porque es un } \\
\text { mugriento pobre", }\end{array}$ & $\begin{array}{l}\text { - "Eres un burro", "Pórtate bien, no } \\
\text { seas un animal","'Cállate, no seas } \\
\text { una placera”, "Deja de jugar no } \\
\text { seas como delincuente”. }\end{array}$ \\
\hline $\begin{array}{l}\text { 5. Max Huárac (48). Docente. I.E. } \\
\text { Parroquial Padre Abad. Tingo María. }\end{array}$ & - "Chato, zonzo, tarado, burro, idiota, negro". & $\begin{array}{l}\text {-"Por su vestir. Porque tienen propina } \\
\text { considerable". }\end{array}$ & $\begin{array}{l}\text { - "Burros porque no aprueban } \\
\text { los exámenes"."Separaban } \\
\text { y castigaban a los alumnos } \\
\text { indisciplinados". }\end{array}$ \\
\hline $\begin{array}{l}\text { 6. Aníbal Poma (35). Docente. I.E. } \\
\text { Daniel A. Carrión, Pasco. }\end{array}$ & - "Enano, estanciero, chaparro", etc. & $\begin{array}{l}\text { - "Porque padres son autoridades del pueblo. } \\
\text { Por tener mayores tierras de cultivo y de } \\
\text { ganadería. Por la edad de los padres." }\end{array}$ & $\begin{array}{l}\text { - Dejado, irresponsable, } \\
\text { chaconero, etc. }\end{array}$ \\
\hline
\end{tabular}

Fuente: Trabajo de campo- cuestionario a profesores. Junio, 2013.

Elaboración: Propia. 
Es que lo "serrano", asi como lo "limeño" y "chuncho" son expresiones bien marcadas en los ámbitos de los alumnos donde lo excluido o marginal es parte de una discriminación racial que se rige no por el color sino por los ámbitos culturales de un origen territorial bien marcado. Y si a esto ańadimos, vestido, economía, poder, quechua, color, cara, pobreza y la higiene, tenemos que las manifestaciones de una población estudiantil se rige por una gran diferenciación socio-cultural donde lo expresivo implica lo racial. Hemos socializado lo racial pero en su sentido discriminatorio, en si un racismo solapado, silencioso y subterráneo, pero que implica el "perfil" de un individuo peruano en la escuela. En cambio, entre el profesor respecto al alumno, el insulto es parte de la evaluación o calificación que merecen los adolescentes: "burro", "animal", "cabeza hueca". Esto condice toda una manifestación del comportamiento de los alumnos en la escuela. Aquí pueden ser dos las precisiones: (a) a quién lo dice y, (b) el por qué lo dice. En muchos casos las experiencias denotan al excluido y al que viene de estratos sociales bajos y hasta de orígenes que denotan rasgos físicos bien marcados por la geografía peruana.

\section{Discriminación étnica racial}

Entre las ideas, que conceptualiza la noción de discriminación, existen dos frases por las cuales los entrevistados obtienen su definición. En su mayoría: "Menosprecio sociocultural hacia otro individuo" y, "Forma de rechazo hacia las personas". Es decir, aquí se juegan dos frases claves, sobre la cual se indica este menosprecio y rechazo. Lo que llama la atención es, que este menosprecio o rechazo puede mostrar sus distintas modalidades muy latentes entre las personas. Una cosa es, cuando la discriminación implica el rechazo. Y, el otro, cuando el menosprecio es por una inter-relación innata en el individuo, quien siempre tendrá su aversión hacia la persona y su autoexclusión permanente porque "lo cholo" y "lo serrano o "lo chuncho" no pueden ser parte de su sentir de interacción, además, de no respeto. Esto, se ve, muchas veces en la ciudad y sobre todo donde las diferencias sociales son muy abismales. Y, por supuesto, el origen de los padres y de los mismos profesores. Por lo tanto, el signo distintivo de la clase social es un primer momento y, segundo la distinción del origen cultural. No la cultura a secas, sino los signos y significados geo-corporeizados, que denotan los individuos frente a otros individuos en tanto, socialmente diferentes. Por lo que, no es casual que las formas de discriminación sea la racial y la cultural la que más denoten, los entrevistados. Y aquí, viene el gran dilema de la racialización, ya que ella conlleva, entender, el color de la piel y la distinción que ella implica en el cabello y en los ojos, por lo que se presenta el gran dilema de quién discrimina a quién. Se trata de un trigueño o es entre trigueños y cobrizos, o de un cobrizo-cholo-"serrano" frente a "otro serrano". Lo que se cruza en este espacio ya no es la piel sino, el "auto-blanqueamiento" cuyo origen es lo social, económicamente hablando, y de la que tanto se describe en la antropología, pero cuyo carácter no tiene el constante denominador de una sociedad europea o estadounidense-anglosajona, sino la de una sociedad, cuyo carácter originario geo-étnico llevan al individuo a impregnarse la idea de superioridad frente a la inferioridad, solamente por denotarse ámbitos geográficos y comportamientos desiguales, pero donde lo económico-social impregna su racialidad.

Desde luego, la discriminación no se disimula, sale a flote y se desenvuelve constantemente, por eso es que los maestros lo denotan casi con el cien por ciento de su región. Mejor decir, todos los pobladores tienen el sentir de ser una ciudad o una región que menosprecia completamente al "otro" pero "entre nos-otros", y más, si se entiende su correlato como menosprecio y rechazo. Es que el color de la piel, no se siente y, más bien es el espacio, el ámbito y la misma piel la que homogeniza. Pero de dónde, entonces, brota la desigualdad. Esto sale, por el lado del dinero y del ámbito social y una subjetividad colonizada que interioriza cada vez más el menosprecio. He allí el quid del asunto supuestamente racial. No es casual, que las dos alternativas, en mayoría para entender esta "racialización" es, "Por el ámbito geográfico de residencia" y, "Por las diferencias socio económicas". Creo, que más sensatos, no pueden ser los mismos entrevistados. Aquí, lo que se entiende por ámbito geográfico no es sino la idea de costa-sierra, o esta racialización desde lo "serrano" como estigma de una racialización o desprecio con antecedentes colonializados aún en boga.

\section{Las palabras claves: serrano, indio, cholo y chuncho}

En este acápite se trata de relacionar las palabras tantas veces usadas desde su sentido racial o como parte de la discriminación que en ella se manifiesta. Trato de indicar, desde la antropología, lo que en uno de sus textos 
Cecilia Méndez (2010) desde la historia, se preguntaba: ¿en qué momento el término serrano fue sinónimo de indio en el Perú? O en realidad, ¿en qué momento el término serrano se convirtió en un insulto ${ }^{28}$. Esta propuesta la desarrolló muy bien dicha autora, que explica que esa acepción racista y geográfica se asienta durante el siglo XIX, o más claro durante el periodo republicano y no en el periodo colonial, donde más bien se ubicaba una suerte de aristocracia andina o mundo criollo indígena, que aún no entraba en ese juego racial geográfico que se vio con mucha más agudeza durante el siglo XX. Méndez, concurre a la pictografía y sobre todo, la literatura criolla y el Mercurio Peruano para explicarnos como estas acepciones prácticamente tienen un encaje histórico que hasta la actualidad persiste. No solamente, en el discurso o el imaginario de los dominantes sino aún en quienes son los dominados y expoliados a nivel geográfico por el centralismo económico y político limeño. Así, la etnografía prácticamente nos pone entre la espada y la pared, ya que los términos tantas veces sugerentes dentro del insulto y sus manifestaciones racistas se toman como sinónimos. Todas las expresiones que hemos entresacado al azar nos sugieren el carácter geográfico de la racialidad. Incluso uno de los profesores se auto-describe y dice que el serrano: "Es una persona que proviene de la sierra como

28 Ver: Méndez, Cecilia. (2010). De indio a serrano: nociones de raza y geografía en el Perú. (Siglo XVIII al XXI). Lima. Rev. Histórica. PUC. yo". Es decir, si bien hay un reconocimiento de que lo "serrano", lo "cholo" y lo "indio" son nociones que se utilizan en su sentido despectivo, se trata de ubicar en dichas significaciones su manifestación optimista que se da a los grupos supeditados. Comprendiendo a la vez, que la palabra "cholo" se asocia siempre con lo "serrano". Es, curioso porque un poblador de la costa no se le endilga dicha frase, cuando en realidad dicha noción es constante en la población. Lo que más bien cobra mayor dimensión, también por el ámbito geográfico, es la palabra "chuncho", que más parecen darle una explicación que casi linda con lo peyorativo: "Persona tímida, callada, poco comunicativa". Y donde las palabras, "selvático", "salvaje", y, la expresión, "son de etnia amazónica", se dejan percibir como gruesos referentes, que prácticamente se despunta con lo racial.

\section{Otros sentidos de discriminación negativa}

Entre las frases que se propaga desde los textos de Sebastián Lorente (1855) encontramos las siguientes: "Un ser llevado por el mal" (malos). "Estúpida llama" (estúpidos). "Llamas que hablan" (animales que hablan). "Tienen los vicios del estado salvaje" (salvajes). "Ignorantes", "Sin entrañas", "Holgazanes", "Rateros", "Sin respeto por la verdad" (mentirosos). "Viven en la embriaguez" (borrachos), entre otras duras frases. En sí, ¿qué relación tienen estas palabras que Lorente propo-

TABLA 4: PALABRAS CLAVE: CHOLO, INDIO Y SERRANO.

\begin{tabular}{|c|c|c|c|c|}
\hline & "Serrano" & "Cholo" & "Indio" & "Chuncho" \\
\hline $\begin{array}{l}\text { 1. Alejandro Duran } \\
\text { Nieves. (58). Docente. } \\
\text { UDH. }\end{array}$ & -"Poblador de zona Sierra." & $\begin{array}{l}\text { - "Forma despectiva de llamar al } \\
\text { poblador de la sierra". }\end{array}$ & $\begin{array}{l}\text { - "Término despectivo para } \\
\text { el poblador alto andino que } \\
\text { no tiene educación alguna”. }\end{array}$ & $\begin{array}{l}\text { - "Poblador selvático que pertenece a } \\
\text { una etnia amazónica" }\end{array}$ \\
\hline $\begin{array}{l}\text { 2. Omar Quispe. (24). } \\
\text { Docente. I.E. Leoncio } \\
\text { Prado. }\end{array}$ & $\begin{array}{l}\text { - "Es una persona que proviene de la } \\
\text { Sierra como yo. Puede considerarse } \\
\text { despectivo en cierto ámbito, pero a mi } \\
\text { criterio sería lo que somos". }\end{array}$ & $\begin{array}{l}\text {-"Significa una persona fuerte, } \\
\text { parte de nuestro origen, una } \\
\text { persona trabajadora que ha } \\
\text { hecho mucho por nuestro país". }\end{array}$ & $\begin{array}{l}\text { - "Fue un indígena el cual no } \\
\text { tuvo muchas oportunidades } \\
\text { y se sumergió en la } \\
\text { ignorancia". }\end{array}$ & $\begin{array}{l}\text {-"El indígena proveniente de la } \\
\text { selva". }\end{array}$ \\
\hline $\begin{array}{l}\text { 3. Stiven Ibarra. (27). } \\
\text { Docente. C.N. UNHEVAL }\end{array}$ & $\begin{array}{l}\text { - "Proviene de la serranía y por lo tanto } \\
\text { te vistes asi". }\end{array}$ & $\begin{array}{l}\text { - "En sus inicios Perro. Era'perro } \\
\text { chusco' de panamá". }\end{array}$ & -"Indio, nativo oriundo". & -"Nativo originario de la selva". \\
\hline $\begin{array}{l}\text { 4. Javier Portugal ( } 29) \text {. } \\
\text { Docente. Secundaria. }\end{array}$ & $\begin{array}{l}\text { - "Haber nacido en la sierra. Son } \\
\text { personas de trabajo y estudio". }\end{array}$ & $\begin{array}{l}\text { - “Discriminación, hacia } \\
\text { mayormente una persona de } \\
\text { origen serrano". }\end{array}$ & $\begin{array}{l}\text { - "Frase discriminatoria hacia } \\
\text { la otra persona por haber } \\
\text { nacido en la Sierra". }\end{array}$ & $\begin{array}{l}\text {-"Persona, tímida, callada, poco } \\
\text { comunicativa". }\end{array}$ \\
\hline $\begin{array}{l}\text { 5. Max Huàrac (48). } \\
\text { Docente. I.E. Parroquial } \\
\text { Padre Abad. Tingo Marìa. }\end{array}$ & -"Proviene de la sierra"- & $\begin{array}{l}\text { - "Es el color mestizo de las } \\
\text { personas". }\end{array}$ & $\begin{array}{l}\text { - "Personas que provienen } \\
\text { de las zonas alto andinas. } \\
\text { Campesinos de zonas } \\
\text { rurales". }\end{array}$ & $\begin{array}{l}\text { - "Es un término de trato que se les } \\
\text { da a los selváticos". }\end{array}$ \\
\hline $\begin{array}{l}\text { 6. Aníbal Poma (35). } \\
\text { Docente. I.E. Daniel A. } \\
\text { Carrión, Pasco. }\end{array}$ & $\begin{array}{l}\text { - "Persona de zona alta, quemado } \\
\text { el rostro, campesino } 0 \text { agricultor e } \\
\text { ingenuo". }\end{array}$ & $\begin{array}{l}\text { - "Cholo serrano, chaposo, } \\
\text { ingenuo, viste con el llanqui, es } \\
\text { muy peculiar en su habla, etc." }\end{array}$ & $\begin{array}{l}\text { - "Vive en las punas, pasta } \\
\text { su ganado, sin estudios, } \\
\text { ignorante". }\end{array}$ & -"Selvático salvaje". \\
\hline
\end{tabular}


TABLA 5: OTRAS FRASES DISCRIMINATORIAS DESDE LAS RELACIONES DE TRABAJO

\begin{tabular}{|c|c|c|c|c|}
\hline & "Serranos son trabajadores" & "Serranos son borrachos" & "Criollos son ociosos" & "cholo de M ..." \\
\hline $\begin{array}{l}\text { 1. Alejandro Duran } \\
\text { Nieves. (58). Docente. } \\
\text { UDH. }\end{array}$ & $\begin{array}{l}\text { - "Trabaja la tierra de luz a luz, que } \\
\text { mastica su coca sin sentir hambre } \\
\text { ni cansancio" }\end{array}$ & $\begin{array}{l}\text { - "Vive en lo borracho para } \\
\text { olvidarse de sus problemas". }\end{array}$ & $\begin{array}{l}\text { - "Se dice que los criollos viven de } \\
\text { los trabajos de los serranos". }\end{array}$ & $\begin{array}{l}\text { - "Frase despectiva que se dan en } \\
\text { ocasiones al poblador andino por } \\
\text { alguna acción que ha realizado } \\
\text { mal". }\end{array}$ \\
\hline $\begin{array}{l}\text { 2. Omar Quispe. (24). } \\
\text { Docente. I.E. Leoncio } \\
\text { Prado. }\end{array}$ & $\begin{array}{l}\text { - "Raza trabajadora, que tenemos } \\
\text { en cuenta que el éxito está en } \\
\text { nuestras manos y no en la simple } \\
\text { suerte" }\end{array}$ & $\begin{array}{l}\text { - "Somos gente alegre que } \\
\text { expresamos nuestro sentir algo } \\
\text { exagerado. Nuestras fiestas son } \\
\text { de una semana con harta comida, } \\
\text { haciendo de cuenta que nos reina } \\
\text { la abundancia." }\end{array}$ & $\begin{array}{l}\text { - "Son ociosos porque se han } \\
\text { aprovechado del indio para } \\
\text { satisfacer sus intereses" }\end{array}$ & $\begin{array}{l}\text { - "Es un despectivo originado } \\
\text { por una clase que se creyó muy } \\
\text { superior, pero que no se supo mirar } \\
\text { al espejo". }\end{array}$ \\
\hline $\begin{array}{l}\text { 3. Stiven Ibarra. (27). } \\
\text { Docente. C.N. UNHEVAL }\end{array}$ & $\begin{array}{l}\text { - "Por su geografía están obligados } \\
\text { a trabajar para subsistir y satisfacer } \\
\text { sus necesidades y por eso mismo } \\
\text { la costumbre de trabajar duro está } \\
\text { enquistado en todo serrano". }\end{array}$ & $\begin{array}{l}\text {-"La borrachera depende de las } \\
\text { circunstancias, el momento y el } \\
\text { espacio donde se encuentre". }\end{array}$ & $\begin{array}{l}\text {-"La historia dice, que eran la clase } \\
\text { parasitaria que se aprovechaban } \\
\text { del indio para obtener su riqueza". }\end{array}$ & - "Grado de inferioridad". \\
\hline $\begin{array}{l}\text { 4. Javier Portugal (29). } \\
\text { Docente. Secundaria. }\end{array}$ & $\begin{array}{l}\text { - "Todas las personas tienen } \\
\text { instinto de trabajo. Aunque en } \\
\text { la sociedad existen personas que } \\
\text { trabajan y no trabajan" }\end{array}$ & $\begin{array}{l}\text {-“Cierta parte de la población } \\
\text { beben en abundancia por motivos } \\
\text { mayormente individuales". }\end{array}$ & $\begin{array}{l}\text {-"Varias personas extranjeras } \\
\text { nacidas en el Perú son vividores, } \\
\text { ociosos que viven de lo fácil } \\
\text { aunque muchos no lo son". }\end{array}$ & $\begin{array}{l}\text {-"Frase ofensiva que se la da a } \\
\text { la persona nacida en la sierra del } \\
\text { Perú". }\end{array}$ \\
\hline $\begin{array}{l}\text { 5. Max Huàrac (48). } \\
\text { Docente. I.E. Parroquial } \\
\text { Padre Abad. Tingo María. }\end{array}$ & $\begin{array}{l}\text { - "Son auténticos y genuinos } \\
\text { trabajadores porque están en } \\
\text { constante actividad laboral de } \\
\text { diferente índole". }\end{array}$ & $\begin{array}{l}\text { - "La gran mayoría de ellos no } \\
\text { lo son. Si existen algunos es } \\
\text { solamente por razones ancestrales } \\
\text { o de costumbres". }\end{array}$ & $\begin{array}{l}\text {-"Algunos lo son. Pero sus } \\
\text { actividades son laboriosas". }\end{array}$ & $\begin{array}{l}\text { - "Es la comparación que se le hace } \\
\text { a la persona mestiza } 0 \text { andina con } \\
\text { el excremento caca". }\end{array}$ \\
\hline $\begin{array}{l}\text { 6. Aníbal Poma (35). } \\
\text { Docente. I.E. Daniel A. } \\
\text { Carrión, Pasco. }\end{array}$ & $\begin{array}{l}\text {-"Porque labran las tierras. Crían } \\
\text { los animales en sus campos. Son } \\
\text { entusiastas. Logran sus metas." }\end{array}$ & $\begin{array}{l}\text { - "Se cree porque vienen de zonas } \\
\text { altas y hacen pagos a la tierra con } \\
\text { ritos de coca y trago. Hoy en día lo } \\
\text { hacen mesuradamente en la fiesta } \\
\text { de sus pueblos". }\end{array}$ & $\begin{array}{l}\text { - "No. Porque vivían en las } \\
\text { ciudades y tenían que trabajar } \\
\text { y en otros casos estudiar para } \\
\text { mantenerse en su clase". }\end{array}$ & $\begin{array}{l}\text {-“No sirve para nada, ignorante, } \\
\text { sin conocimientos". }\end{array}$ \\
\hline
\end{tabular}

Fuente: Trabajo de campo- cuestionario a profesores. Junio, 2013. Elaboración: Propia.

ne explicar para la sociedad andina-peruana de la época con las percepciones que se presentan en el imaginario regional de los maestros de Huánuco?, ¿cómo se puede percibir dichas expresiones, que provienen de la intelectualidad del siglo XIX con lo que observan los maestros, en sus alumnos, en el aula? Desde luego, contextos históricos socio-culturales diferentes, pero con significados que se arrastran desde entonces hasta la actualidad en la escuela peruana ${ }^{29}$.

En realidad, se trata de ver la contrapartida con dichas voces del siglo XIX, desde un sentido más reivindicativo. Se inicia así, una fuerte complejidad para tratar de distinguir el sentido despectivo regional que continuamente se manifiesta desde un contexto social, cultural y étnico, frente a la contraposición solidaria o bajo una reivindicación étnica y originaria que los mismos profesores expresan. Es decir, da la sensación que

29 No estamos dejando de lado, el recorrido histórico colonial que implica sus inicios en el siglo XVI. Incluso bien lo podemos rastrear desde los Diarios de Colón, pasando por Garcilaso de la Vega, llegando hasta el XXI. Lorente es un pretexto republicano. en algún momento, se cae en la discriminación a cuestas, mientras en otro momento a la pregunta, "¿qué significa para Ud. los serranos son trabajadores?”. Las respuestas cuasi por consenso son: "Trabaja la tierra de luz a luz, y mastica su coca sin sentir hambre ni cansancio"; "Raza trabajadora, que tenemos en cuenta que el éxito está en nuestras manos y no en la simple suerte"; "Son auténticos y genuinos trabajadores porque están en constante actividad laboral de diferente indole". Y para contraponer la frase, "viven en la embriaguez" de Lorente; uno de los maestros respondería de la siguiente manera: "Somos gente alegre que expresamos nuestro sentir algo exagerado. Nuestras fiestas son de una semana con harta comida, haciendo de cuenta que nos reina la abundancia"so.

30 En uno de los escritos de José Ángel Escalante, en plena polémica del indigenismo, se lee: "El indio no es alcohólico. Bebe menos que el blanco y el miste. En las cantinas de la Capital se bebe, en una mańana de invierno, entre once y una del día, más alcohol que en una festividad de pueblo serrano o en una 'thinca' de ganado, en las estancias de la puna, donde se reúnen cientos de indígenas. ¿Quién será capaz de sostener lo contrario? El blanco y el miste beben todos 
TABLA 6: REFERENTES GENERALES DE LOS SUJETOS SOCIALES ENCUESTADOS.

\begin{tabular}{|l|l|}
\hline \multicolumn{1}{|c|}{ Concepto/Ideas } & \multicolumn{1}{c|}{ Referencias generales } \\
\hline Lugar de nacimiento & $\begin{array}{l}\text { Huánuco (75.0\%), Pasco (2.3\%), Moquegua (2.3\%), San Pedro de Chala (2.3\%), Aparicio Pomares (2.3\%), Quinilla (2.3\%), Huancabamba } \\
(2.3 \%), \text { Oroya (2.3\%), Margos (2.3\%), Ucayali (2.3\%) y, Lauricocha (2.3\%). }\end{array}$ \\
\hline Edades & De 18 a 25 años (4.2\%); De 26 a 45 años (66.7\%); De 46 a más años (29.2\%) \\
\hline Nivel de estudio & Superior completo (83.7\%); Maestría (4.7\%); Postgrado (11.6\%) \\
\hline Ocupación & $\begin{array}{l}\text { Docente (79.9\%); Jefe Administrativa (2.2\%); Independiente (2.2\%); Doctora (2.2\%); Contador (2.2\%); Empleado (2.2\%);; Ing. Ambiental } \\
(2.2 \%) ; \text { Administrador (2.2\%); Consultor (2.2\%); Agro Industrial (2.2\%) }\end{array}$ \\
\hline Sexo & El 52.8\% de los maestros pertenecen al sexo masculino y el 47.2\% pertenecen al sexo femenino. \\
\hline Idioma & Castellano (82.0\%); Quechua (16.2\%); y Aimara (2.0\%) \\
\hline Religión & Católica (94.1\%); Evangélica (3.9\%); Pentecostal (2.0\%) \\
\hline I.E.P. donde labora actualmente & $\begin{array}{l}\text { I.E.P. Leoncio Prado Gutiérrez (14.8\%); IE Nº 32169 Maraypata (3.7\%); La Divina Misericordia (3.7\%); Puerto Inca (3.7\%); Julio Armando } \\
\text { Ruiz Vásquez (3.7\%); Cesar Vallejo (3.7\%)* }\end{array}$ \\
\hline
\end{tabular}

Ver: Encuesta: Tablas: 1.1; 1.2; 1.3; 1.4-1.6; 1.7 y 1.5. También Gráfico 1. (Informe IIHS, 2014)

Fuente: Encuesta. Noviembre 2014. Elaboración: Propia.

* $\quad$ El resto de encuestados responden, en el siguiente orden: Juan Crespo Castillo (Huanca Pampa) (3.7\%); Juana Moreno (3.7\%); Horacio Zevallos Gámez (3.7\%); Alto Chipa (3.7\%); Las Pachas (3.7\%); Túpac Amaru II (3.7\%); Atahualpa (3.7\%); Julio Armando Ruiz (3.7\%); Puente Doran Chinchao (3.7\%); I. E. Municipalidad (3.7\%); Consorcio Externo (3.7\%); Asistente Administrativa (3.7\%); Dirección Regional de Transporte y Comunicaciones Huánuco (3.7\%); ONG Construyendo tu Futuro Corporación Atomic IDI SAC (3.7\%); 0tros (14.8\%).

Y más bien, es la locución, hacia los criollos —en sentido genérico- desde la que salen mal parados frente a la pregunta: “¿los criollos son ociosos?”. Las respuestas de los maestros refieren: "Son ociosos porque se han aprovechado del indio para satisfacer sus intereses"; y otro maestro diría: "La historia dice, que eran la clase parasitaria que se aprovechaban del indio para obtener su riqueza". Y para relacionar esta idea de lo criollo con el poder preguntamos: qué significado da a la siguiente expresión: "el criollo siempre piensa en el poder". Una de las respuestas fue contundente: "La ambición de la clase aristocrática (criolla) era temible, casi despiada$d a$ ". No solamente estamos en función a las respuestas que tuvieran los maestros frente a Lorente, sino con ello toda una carga despectiva que entre los alumnos se observa y que los contextos regionales aún a pesar de ser solidarios y fraternos, lo expresan como si aún, continuaríamos en la línea del autor del siglo XIX en mención. Y los más expresivo se manifiesta, cuando se pregunta sobre la frase: "cholo de m...". Aquí se mira, como una frase despectiva que se les endilgan a los pobladores de la Sierra, desde un sentido de superioridad de quienes lo dicen. En este aspecto, parece existir una intersubjetividad respecto a lo cholo desde una relación geográfica que implica menosprecio y jerarquía social. No solo se entiende como lo que podemos ubicar en la parte Costa donde la idea de "cholo" puede tener con-

los días, por hábito, por necesidad orgánica o por exigencia social; el indio solo bebe de tarde en tarde; los domingos, cuando descansa de las faenas rurales; en las festividades religiosas, provocadas por la sordidez del cura y las asociaciones pías; en las faenas agrícolas que se festejan tradicionalmente desde los tiempos incaicos." (Escalante, La Prensa 3 de febrero de 1927. En: Aquézolo, 1976: 41) notación distinta y muchas veces hasta de afectividad y halago.

\section{Lo cuantitativo: Referencias generales de los sujetos sociales encuestados}

Asimismo, si observamos la siguiente Tabla no se ven distinciones abismales entre lo que se responde desde los testimonios ${ }^{31}$ de modo abierto y los encuestados. Sin embargo, los que se quieren distinguir por la profesión inicial y, que no quieren identificarse como maestros, no son más del veinte por ciento. Tampoco, quiere decir que estén fuera de las aulas. Todos o, en gran parte, sostenían enseñar en colegios, salvo algunos pocos, que nos explicaban trabajar en institutos superiores. Además, los que sostenían que estudiaban maestría y/o posgrado, podemos reunirlos en un solo bloque de más o menos un dieciséis por ciento, pero en realidad, son de preferencia maestros en plena actividad. De todos modos, son cerca del ochenta por ciento que se asumen como docentes. Esto teniendo presente que son los mismos docentes -indicaban entoncesque estaban en plena capacitación pedagógica ${ }^{32}$.

31 Cuando me refiero a los testimonios, indico a los que respondieron las preguntas abiertas y son exclusivamente los maestros de la Universidad de Huánuco que estudiaban maestría en Investigación y Docencia Superior, por entonces.

32 Los resultados de la encuesta se encuentran en el repositorio del IIHS de la Facultad de Ciencias Sociales, cuyo proyecto se ejecutó el año 2014, con el título: La subjetividad racial y racista en la educación peruana. Una percepción desde los maestros de la Región Huánuco. El código de estudio es el: 141501161. Entre los miembros contamos con Sabino Arroyo y Julio Mejía y los alumnos colaboradores: Aldo Pecho y Nekson Pimentel. 


\section{TABLA 7: LA IDEA DE EDUCACION}

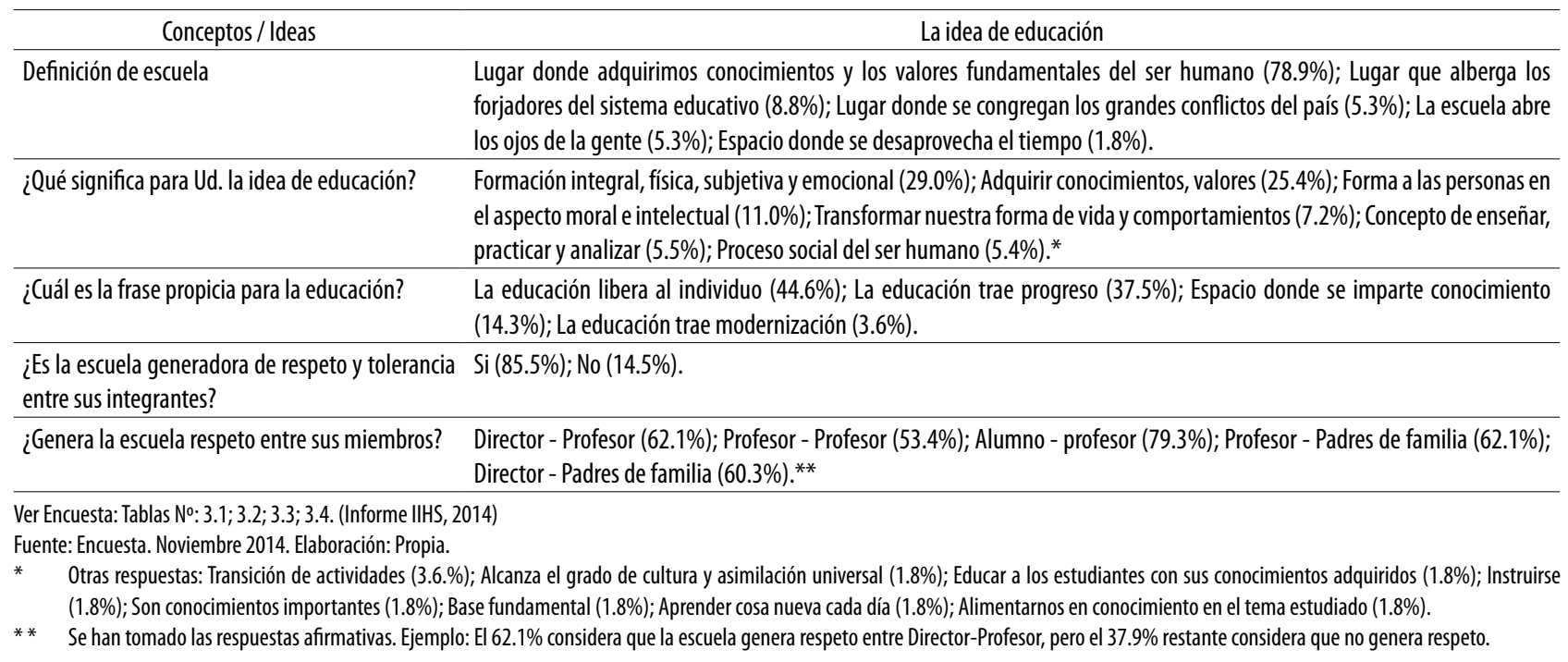

\section{El significado de la tolerancia y el respeto en la escuela}

Cuando entramos a la parte cuantitativa, ya con las preguntas estructuradas y medibles, se observa una percepción mejor marcada de la escuela, donde en su mayoría lo ven como el "Lugar donde adquirimos conocimientos y los valores fundamentales del ser humano". Es decir, se trata de ubicar a la escuela como el espacio propicio que libera al individuo y que genera "progreso". Si seguimos sus definiciones. En el fondo, si bien los entrevistados con preguntas abiertas, nos correspondían con las formas de falta de respeto y la pérdida de valores entre sus miembros, en esta parte numérica encontramos que la mayoría de ellos, por encima del sesenta por ciento nos explican que la escuela genera respeto y valores entre todos sus miembros que la conforman. Como se ve, tenemos dos explicaciones, que pueden ser contradictorias, pero que en el fondo son parte complementaria de un mundo que se mueve en las dos formas de convivencia, en todos los ámbitos. Es decir, de lo que se trata es de observar dónde se imprime la primacía de lo que puede suceder en grado extremo en caso de que la pérdida de noción de escuela quede rezagada por completo. De hecho, se tiene en el imaginario que la escuela genera sentimientos de otro tipo de individuo y sociedad, pero muchas veces puede suceder lo contrario: el ámbito de generar jerarquización y supeditación que se asume inconscientemente, al margen del ideal que los medios imprimen a la escuela, como sentido de humanidad. Incluso, aquí se presenta una gran inquietud por las respuestas de los profesores, cuando se les preguntaba de manera individual o en el cuestionario abierto sobre el respeto que se generaba entre profesores, podemos decir que las respuestas eran para explicarnos sus rencillas al interior de cada centro educativo. Pero, cuando, se les pregunta en la encuesta, las cifras dicen lo contrario, lo que quiere decir el abanico contradictorio en la que se manejan cuando se dicen las cosas de frente y sin tanto ambaje, mientras que en las cifras estadísticas sostienen en su mayoría que los conflictos existen o las contraposiciones entre sus miembros es de menor escala. Aquí se puede inferir, que se trata de ver una escuela más sólida y activa en sus principios y, en sus "valores" y uno de ellos es el respeto y la tolerancia. De todos modos, encontramos que, la escuela aún sigue siendo parte de la idea de "libertad individual" y de "progreso". Dos conceptos, sobre la cual el mundo moderno y liberal se construye, además sobre la cual nuestros padres inculcan el éxito y el futuro de los hijos, sintiendo aún que el conocimiento es parte de salir del estancamiento social o como sinónimo de estatus social.

\section{La discriminación en cifras desde los maestros}

Las cifras demuestran que es muy común escuchar las palabras racistas entre alumnos. Lo que concuerda con todas las denominaciones que se han realizado al respecto. En realidad, son más del noventa por ciento que siente que estas palabras o frases e, incluso injurias entres los alumnos están a la orden del día. Muy pocos son los que se relegan en decir, que no han sido 
TABLA 8: RACISMO Y DISCRIMINACIÓN ENTRE ALUMNOS Y PROFESORES

\begin{tabular}{|c|c|}
\hline Conceptos / Ideas & Racismo y discriminación entre alumnos y profesores \\
\hline $\begin{array}{l}\text { ¿Ha escuchado palabras racistas que se } \\
\text { endilgan entre alumnos? }\end{array}$ & Si (91.4\%); № (8.6\%). \\
\hline $\begin{array}{l}\text { Primera palabra racista que se expresan entre } \\
\text { los alumnos }\end{array}$ & $\begin{array}{l}\text { Cholo (26.4\%); Shuco (22.6\%); Negro (9.4\%); Serrano (5.7\%); Indio (3.8\%); Inútil (3.8\%); Gordo (3.8\%); Por el color de la piel } \\
\text { (1.9\%); Chatas (1.9\%); Enano (1.9\%); Pobre (1.9\%); Tarado (1.9\%); Feo (1.9\%); Llama (1.9\%); Bruto (1.9\%); Sobón (1.9\%); } \\
\text { Eres de la chacra (1.9\%); Panuco (1.9\%); Piraña (1.9\%); Lento (1.9\%). }\end{array}$ \\
\hline $\begin{array}{l}\text { ¿Ha observado la discriminación de los } \\
\text { profesores hacia los alumnos? }\end{array}$ & Si (51.8\%); № (48.2\%) \\
\hline $\begin{array}{l}\text { Forma que los profesores discriminan a los } \\
\text { alumnos }\end{array}$ & $\begin{array}{l}\text { Por su forma de vestir (23.5\%); Por su apellido originario (17.6\%); Por la economía de los padres (17.6\%); Por el idioma } \\
\text { quechua (14.7\%); Por el cabello negro y rostro chaposo (11.8\%); Por el color de su piel (8.8\%); Por su idioma originario (5.9\%). }\end{array}$ \\
\hline
\end{tabular}

Ver Encuesta: Tablas: 4.1; 4.2; Gráfico 6; 7. (Informe IIHS, 2014)

Fuente: Encuesta. Noviembre 2014. Elaboración: Propia.

proclives a tanta tentación agresiva. Y aquí, lo primero, que sale a relucir es la palabra "cholo". Pero hay que tener cuidado porque estamos con profesores de la sierra huanuqueña donde, los indicios testimoniales ponían el sujeto "cholo" como el sentido de lo serrano o de lo andino, por lo que no nos puede preocupar la noción de "serrano e indio" rezagada a un nueve por ciento en total. Más bien lo que se hace sinónimo de todo ello es la palabra "shuco" cuya definición, es más agresiva e intolerante, sobre todo cuando se trata de pobladores recién bajados de las partes altas de Huánuco. Las respuestas que se manifiestan de la discriminación de los profesores hacia los alumnos, parecen quedar casi empatados en un cincuenta por ciento entrambos, de todos modos los maestros dicen que la discriminación viene, por el vestir en mayoría, pero a la vez, seguido del apellido originario, la economía de los padres y, el idioma quechua. En realidad, son los elementos centrales de cómo la racialización bajo el insulto o el agravio se hace presente. Lo que conlleva explicarnos, que hablar de discriminación tiene que ser visto en todos los ángulos posibles. El problema es cuando esto pasa a ser parte del lenguaje común y de la mirada agresiva que ella implica.

\section{Lo "serrano" y lo "cholo" como sentidos de discriminación}

Cuando la pregunta comienza a especificarse y se habla de discriminación bajo alternativas estructuradas, sale a relucir la palabra "serrano" y "cholo" como acepciones de discriminación. Esto quiere decir que las palabras siguen en la cabeza con mayor fuerza y como sentido común de una población que lo lleva perenemente. Esto, se da la mano, con frases como "eres de la puna" y "fuera sucho" que indican de igual modo el despectivo o desprecio más desagradable de la región. Quedando más bien, relegados el sentido insultante de "ignorante de m..." y "burro" o "pobreza", expresiones que son más bien insolencias, no obstante discriminatorias en lo social y económico. Y cuando, se le solicitan que pongan las frases racistas discriminatorias de la región nuevamente salen a la palestra tres: "Shuco" en mayoría y, "Serrano y Cholo" en forma continua, lo que corrobora cuan interiorizado tienen en la subjetividad estas palabras que parecen ser, la comidilla del día entre los maestros y alumnos de Huánuco, sin indicar acepciones alternativas que excluyan su sentido agresivo. Y más cuando observamos la pregunta que se les hace e indican las palabras con las que fueron discriminados en su región son las mismas pero en distinto orden: "Serrano; Cholo; Shuco". Como se ve la regionalización viene por la palabra "shuco". Y, más bien, lo que escuchábamos constantemente en Lima en los años ochenta de "llama" y "alpaca" como lo zoo-racializado, parecen quedar en la historia de la región y diríamos, excluyéndolos totalmente. Lo destacable es, que cuando se les pregunta a los maestros si fueron discriminados en su lugar de origen ellos en mayoría dicen que no. Aunque hay un cierto porcentaje (más del cuarenta por ciento) que responde positivamente. De igual modo, sucede cuando se le pregunta si fueron discriminados en su escuela, como centro de trabajo. No se admite ningún tipo de discriminación. Es, lo que siempre queremos ocultar entre nosotros. Nunca admitimos ni autocríticamente que somos parte de este mundo donde la subjetividad es parte de un entorno hostil, agresivo, insultante y humillante. En realidad, nadie le gustaría vivir la agresividad de la dominación, pero en el fondo se trata de quienes piensan que tienen la supremacía para pensarse superiores buscando un resquicio que les de espacio para fomentarse mode- 
TABLA 9: PALABRAS O FRASES DISCRIMINATORIAS EN LA ESCUELA

\begin{tabular}{|c|c|}
\hline Conceptos / Ideas & Palabras o frases discriminatorias en la escuela \\
\hline $\begin{array}{l}\text { Primera palabra que ha escuchado de manera } \\
\text { discriminatoria en la escuela. }\end{array}$ & Cholo (36.6\%); Serrano (53.7\%); Chuncho (2.4\%); Indio (4.9\%); Negro (2.4\%) \\
\hline $\begin{array}{l}\text { Primera frase discriminatoria que ha escuchado en } \\
\text { la escuela }\end{array}$ & $\begin{array}{l}\text { Eres de la puna (31.8\%); Fuera sucho (22.7\%); Ignorante de mierda (13.6\%); Eres un burro }(11.4 \%) \text {; Tus papás son } \\
\text { pobres }(9.1 \%) \text {; Negro asqueroso (6.8\%); Fuera chuncho }(2.3 \%) ; 0 \text { tros }(2.3 \%)\end{array}$ \\
\hline $\begin{array}{l}\text { Describa y defina la primera frase discriminatoria } 0, \\
\text { racista que se utiliza en su región }\end{array}$ & $\begin{array}{l}\text { Shuco (30.6\%); Serrano (26.5\%); Cholo (22.4\%); Llama (4.1\%); Ignorantes (2.0\%); Gente blanca (2.0\%); Incapaz } \\
\text { (2.0\%); Chocona (2.0\%); Hombre mono (2.0\%); Apestoso (2.0\%); Placera (.20\%); Somos de capital (2.0\%). }\end{array}$ \\
\hline ¿Ha sido Ud. discriminado en su lugar de origen? & Si (46.6\%); No (53.4\%). \\
\hline $\begin{array}{l}\text { Primera palabra con la que fue discriminado en su } \\
\text { lugar de origen }\end{array}$ & $\begin{array}{l}\text { Serrano (28.0\%); Cholo (16.0\%); Shuco (12.0\%); Negro (4.0\%); Pata amarilla (4.0\%); Huanuqueño (4.0\%); Chato } \\
\text { (4.0\%); Incapaz (4.0\%); Zambo (4.0\%); Creída (8.0\%); Borracho (4.0\%); Provinciano (4.0\%); Desnutrido (4.0\%). }\end{array}$ \\
\hline $\begin{array}{l}\text { ¿Ha sido Ud. discriminado con algunas palabras } \\
\text { racistas fuera de su escuela de trabajo? }\end{array}$ & Si (41.5\%); № (58.5\%) \\
\hline $\begin{array}{l}\text { Primera palabra con la que fue discriminado } \\
\text { racistamente fuera de su escuela de trabajo }\end{array}$ & $\begin{array}{l}\text { Cholo (42.9\%); Negro (14.3\%); Indio (9.5\%); Tacaño (4.8\%); Enano (4.8\%); Crudo de mierda (4.8\%); No se aceptan } \\
\text { alquiler por tener un hijo (4.8\%); Shuco (4.8\%); No eres de este partido político (4.8\%); Simba (4.8\%). }\end{array}$ \\
\hline $\begin{array}{l}\text { ¿Ha sido Ud. discriminado con alguna palabra racista } \\
\text { en su escuela de trabajo? }\end{array}$ & Si (25.5\%); № (74.5\%) \\
\hline $\begin{array}{l}\text { Primera palabra con la que fue discriminado } \\
\text { racistamente en su escuela de trabajo }\end{array}$ & $\begin{array}{l}\text { Para los que respondieron N0 (25.5\%): Indio (21.4\%); Chola (14.3\%), Negro (7.1\%); El ogro (7.1\%); La manera de } \\
\text { hablar cantando }(7.1 \%) \text {; No eres huanuqueño }(7.1 \%) \text {; Pendenciero (7.1\%); Chato (7.1\%); Creído (7.1\%); Tus papas } \\
\text { son pobres }(7.1 \%) \text {; Shuco (7.1\%). }\end{array}$ \\
\hline
\end{tabular}

Ver Encuesta: Tablas No: 2.4; $2.5 ; 2.6 ; 2.7 ; 2.8 ; 2.9 ;$ Gráficos No:2;3; 4 . (Informe IIHS, 2014)

Fuente: Encuesta. Noviembre 2014.. Elaboración: Propia.

los de superioridad pero a la vez someter y ubicar a "sus inferiores”. ¿Cuánto tiene que ver en esto la televisión "blanca" y sus modelos físico-culturistas de hombres y mujeres que ahora recorre globalmente nuestras regiones? Desde luego, es quien la penetra constantemente en nuestra mentalidad, de tal manera, que solo nos toca advertir y denunciar académicamente el hecho ${ }^{33}$.

\section{Lo regional como expresión de discriminación}

Cuando entramos a las definiciones que se establecen desde la discriminación hay algo que llama la atención. Uno, es que el color de la piel y, la exclusión social se dejan de lado como alternativas y más bien se insiste mucho en el menosprecio y el rechazo. Lo que hace posible ver que en realidad no hablamos de colores ni de situaciones económicas sino de ámbitos culturales que parecen racializar la vida cotidiana. Pero, más que ello, se tendría presente que son en realidad, distintas formas cuasi complementarias que hacen posible tal discriminación y, que implican un complejo en tríada:

33 Gonzalo Portocarrero (2013), interpretando una encarte propagandístico de Ripley describía: "Todo es blanco: la colcha, los pijamas, el pañal. Ellos mismos son también blancos. El bebé, curiosamente, es aun más blanco que sus progenitores. Es rubio. El blanco simboliza la pureza y la inocencia, la modestia y la felicidad. No hay manchas, ni pecados, ni trasfondos oscuros. Todo es como se ve". En realidad, el mercantilismo en su real dimensión, pero el alcance también es el deseo del público, el modelo. Pero hay que ver la forma de instituirlo y su de dominación. Ver: Bibliografía.
TABLA 10: DISCRIMINACIÓN ÉTNICA RACIAL REGIONAL

\begin{tabular}{|c|c|}
\hline Conceptos / Ideas & Discriminación étnica - racial \\
\hline $\begin{array}{l}\text { ¿Qué entiende por } \\
\text { discriminación? }\end{array}$ & $\begin{array}{l}\text { Menosprecio sociocultural hacia otro individuo } \\
(38.6 \%) ; \text { Forma de rechazo hacia las personas } \\
(35.1 \%) ; \text { Desprecio hacia determinadas personas } \\
\text { (14.0\%); Distinción por el color de la piel (10.5\%); } \\
\text { Exclusión social por razones económicas }(1.8 \%) \text {. }\end{array}$ \\
\hline $\begin{array}{l}\text { Formas de discriminación } \\
\text { que observa en el país. }\end{array}$ & $\begin{array}{l}\text { Social (21.1\%); Cultural (22.8\%); Étnico (15.8\%); } \\
\text { Racial (31.6\%); Económico (8.8\%). }\end{array}$ \\
\hline $\begin{array}{l}\text { ¿Existe discriminación en } \\
\text { su región? }\end{array}$ & Si $(98.3 \%) ;$ No $(1.7 \%)$ \\
\hline $\begin{array}{l}\text { Formas que se expresa } \\
\text { la discriminación en su } \\
\text { región }\end{array}$ & $\begin{array}{l}\text { Por el ámbito geográfico de residencia (40.4\%); Por } \\
\text { diferencias socio económicas ( } 40.4 \%) \text {; Por el color } \\
\text { de la piel (17.5\%); Por entonación de voz de las } \\
\text { personas (1.8\%) }\end{array}$ \\
\hline
\end{tabular}

Ver Encuesta: Tablas No: 2.1; 2.2; 2.3; Gráfico № 2;. (Informe IIHS, 2014)

Fuente: Encuesta. Noviembre 2014. Elaboración: Propia.

$\mathrm{racial} /$ cultural/social más cuando explican que la discriminación está a flor de piel o a flor de labios (me refiero a la palabra), en más del noventa por ciento. Esto requiere de una lectura muy aguda, porque se dice que no se "siente" pero se "ve" y, existe. Este es el dilema de una sociedad que busca resistencias que no puede simular, sino aceptar en determinados momentos: el ámbito de residencia y las diferencias económicas son un claro marcador de todo ello, en el fondo distinción de espacios sociales y de estatus y prestigio que implican la geografía y el lugar de vivir. 


\section{TABLA 11: SENTIDO DE LAS PALABRAS Y FRASES ETNO-RACISTAS}

\begin{tabular}{|c|c|}
\hline Conceptos / Ideas & Sentido de las palabras y frases etno-racistas \\
\hline $\begin{array}{l}\text { ¿Para Ud. qué significa la palabrita } \\
\text { "Cholo"? }\end{array}$ & $\begin{array}{l}\text { Humillación para poblador de la sierra (27.8\%); Ser peruano y lo mejor del país (27.8\%); Es el color mestizo de la sierra (16.7\%); } \\
\text { Persona trabaiadora de la sierra (13.0\%) : Serrano peculiar en su habla }(9.3 \%) \text { : Chaposo inaenuo viste con llanaue }(5.6 \%)\end{array}$ \\
\hline $\begin{array}{l}\text { ¿Para Ud. qué significa la frase } \\
\text { "Cholo de m...."? }\end{array}$ & $\begin{array}{l}\text { Despectiva y racista en toda su dimensión (44.6\%); Es frase común en la calle (25.0\%); La expresan los criollos o blancos (23.2\%); № } \\
\text { tiene ninguna importancia para mí (7.1\%). }\end{array}$ \\
\hline $\begin{array}{l}\text { ¿Para Ud. qué significa la palabra } \\
\text { "Serrano"? }\end{array}$ & $\begin{array}{l}\text { Orgullo del Perú (37.5\%); Orgullo provinciano (31.3\%); Son lo peor del país (14.6\%); Nada (6.3\%); Discriminación de los provincianos } \\
(6.3 \%) ; \text { Persona que nació en la sierra (2.1\%); Pertenece a una región (2.1\%). }\end{array}$ \\
\hline $\begin{array}{l}\text { ¿Para Ud. qué significa la frase "los } \\
\text { serranos son trabajadores"? }\end{array}$ & $\begin{array}{l}\text { Raza trabajadora de grandes éxitos (65.4\%); Trabaja la tierra de luz a luz (19.2\%); Una alabanza de mucha hipocresía (11.5\%); } \\
\text { Auténticos dueños del país (3.8\%). }\end{array}$ \\
\hline $\begin{array}{l}\text { ¿Para Ud. qué significa la frase "Los } \\
\text { serranos son borrachos"? }\end{array}$ & $\begin{array}{l}\text { La borrachera existe en todo el mundo y no es propia de los serranos ( } 52.9 \%) \text {; Un insulto de los que se creen blanquitos (29.4\%); Es } \\
\text { parte de la costumbre por razones ancestrales }(9.8 \%) \text {; La alegría de las festividades patronales (3.9\%); Es propia de nuestra cultura } \\
(3.9 \%) \text {. }\end{array}$ \\
\hline $\begin{array}{l}\text { ¿Para Ud. qué significa la frase "Los } \\
\text { criollos son ociosos"? }\end{array}$ & $\begin{array}{l}\text { Que viven de trabajo ajeno (37.5\%); Que se aprovecharon del indio en todo (35.4\%); Que si no trabajarían no serían dueños grandes } \\
\text { empresas (8.3\%); Que es el sector social parasitario del país (8.3\%); Que trabajan y estudian fuerte (6.3\%); Otros (4.2\%). }\end{array}$ \\
\hline $\begin{array}{l}\text { Explique, según Ud. la frase: "Indio, } \\
\text { Ocioso, Haragán y Ladrón". }\end{array}$ & 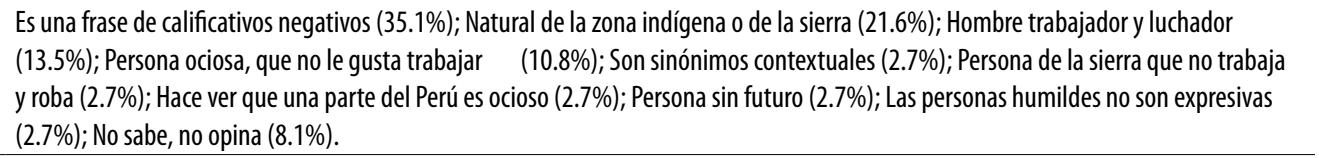 \\
\hline $\begin{array}{l}\text { Explique, según Ud. la frase: } \\
\text { "Chuncho, Salvaje y Bárbaro". }\end{array}$ & $\begin{array}{l}\text { Persona de la selva que no tiene educación, ni trato (24.3\%); Hombre/chuncho de la selva (21.6\%); Persona de la selva que son } \\
\text { violentas/agresivas (8.1\%); Chuncho es palabra denigrante y estigma negativo (8.1\%); Dispositivo selvático (5.4\%); Discriminación a } \\
\text { los nativos o grupos étnicos en siglo XXI (5.4\%).* }\end{array}$ \\
\hline \multicolumn{2}{|c|}{$\begin{array}{l}\text { Ver Encuesta: Tablas No: 5.1; } 5.2 ; 5.3 ; 5.4 ; 5.5 ; 5.6 ; 5.7 ; 5.8 ; \text { Gráfico № 6; 7. (Informe IIHS, 2014) } \\
\text { Fuente: Encuesta. Noviembre 2014. Elaboración: Propia. } \\
\text { Entre otras respuestas refieren los encuestados: Hombre selvático cautivo, amoroso en su ambiente (2.7\%); Persona fuerte (2.7\%); Son frases de expresión individual (2.7\%); Los pobladores de } \\
\text { la selva pertenecen a la civilización de manera equivocada (2.7\%); Con poca capacidad intelectual (2.7\%); Poco sociable (2.7\%); Palabra según el dialecto (2.7\%); No sabe, no opina (5.4\%); Los } \\
\text { adjetivos son los que crean tu imagen (2.7\%). }\end{array}$} \\
\hline
\end{tabular}

\section{Los significados de las palabras y frases etno-racistas}

En este acápite final averiguamos las palabras y frases que más se utilizan como agravios o, como referentes raciales en el país. Es así, que el significado de la palabra "cholo" se asocia como Humillación para el poblador de la sierra y, Ser peruano y lo mejor del país; algo contradictorio por cuanto, se mezclan las dos partes que implican, su discriminación pero a la vez su elevada autoestima. Algo sucede en estas respuestas que no entran en relación con las versiones testimoniales de los maestros donde lo indican como una palabra muy estigmatizada por parte de los estudiantes. Esto es contrario a lo cholo, que se refiere a, El color mestizo de la sierra, que no cobra tanta importancia en términos numéricos. De igual forma sucede con las expresiones "cholo de m...", la cual se responde que es una frase "despectiva y racista" para una gran mayoría de los encuestados; pero que es muy "común en la calle" y que es expresión de "criollos o blancos" en un segundo momento. Esto nos hace deducir que el desprecio más que social es racial y cobra extensión en ámbitos públicos. En realidad lo "cholo", puede ser leído casi de igual manera, que el significado de lo "serrano" cuando se explica que se entiende, como el "orgullo del Perú" y el "orgullo provinciano". Como se ve, también, se expresa en la imagen de los vocablos una relevancia que no podemos dejar de lado, es decir, se tiene en la mente de los profesores que el sentido de Perú y de provincia tiene sus cimientos en una percepción de orgullo que gran parte de nuestra población hace suya. No en vano, podemos orientar cualidades que solo el ingenio y la sensatez hace del país o, de las ciudades otra forma de convivencia y de producción pocas veces vista en países latinoamericanos. Es por esto que se percibe que los "serranos son trabajadores" además de una "raza trabajadora de grandes éxitos" que los coloca frente a los demás grupos como los progresistas, no lejos de los que están pensando en una modernización de la sociedad peruana a su manera. Es decir, que el "trabajo sol a sol" tiene sus resultados y ello se ve en la construcción de ciudades que se ve a lo largo del territorio peruano. Pero eso sí y, algo sintomático, como respuesta es que, "no se sienten los dueños del país". Lo que expresa sus diferencias y el lugar que ocupan como parte de la sociedad. También, por ello a la pregunta de que "los serranos son borrachos" las respuestas implican un desagravio y, es quizás lo que anteriormente se decía 
respecto de que no es exclusividad solamente de grupos determinados. Es decir, la borrachera existe en todo el mundo y no es propio de los "serranos" ${ }^{34}$. Y, cuando requerimos de la respuesta a la frase, "los criollos son ociosos", no entran alocuciones "como propietarios de empresas" o, como "sector social parasitario", lo que tanto fue el estigma de esta gente por parte de los sectores académicos de la izquierda en el país. Sin embargo, no se escapan de ser los, "Que viven de trabajo ajeno y Que se aprovecharon del indio en todo" para la gran mayoría. Pero, es algo reflexivo pensar que lo "indio" cuando se le toma como "haragán”, "ocioso" y "ladrón” es más, una actitud despectiva que implican calificativos negativos en las personas que lo refieren o, en el fondo una defensa más que de lo indio en sí, de la versión de lo "serrano" como sentido social y personal que tanto se estigmatiza. Hay que entender que lo "indio" como noción es muy del siglo XIX y los pobladores de la zona parecen no calificarlos como tal. Salvo si son de las alturas cuando dicen en un segundo momento: que son naturales de la zona indígena o de la sierra. Y hay que observar, que cuando se trata la frase "el chuncho es salvaje y bárbaro" aún se tiene en el pensamiento que la selva por no decir el "salvaje" está asociado a la falta de educación y, el buen trato, por lo tanto violentos y agresivos, si los ponemos en combinación el ser de "origen selvático". Como se ve no se expresan otras categorías por cuanto en estas frases hemos tratado de seguir las mismas palabras de nuestros académicos del siglo XIX.

\section{A modo de reflexiones preliminares}

La investigación nos somete a un test, tanto al investigador como a los investigados. Cuasi todos nos vemos reflejados en las palabras y en los hechos ${ }^{35}$. No tenemos espacio. La colonialidad simbólica de nuestro

34 Quiero dejar constancia que las preguntas se hicieron como un símil en función a lo que Lorente propuso en el libro en referencia que citamos. Otras preguntas se infirieron de las respuestas que propusieron los mismos maestros con cuestionario de preguntas abiertas. Otras expresiones provienen de las experiencias del autor: lo que observo y escucho.

35 En una exposición, sobre el tema, en sus clases de doctorado en noviembre del presente año, Jürgen Golte, me preguntaba y ¿qué resultaría si le hacemos las mismas preguntas a los alumnos de la facultad de ciencias sociales? $Y$ de paso me increpaba haber referido a tal profesor el calificativo de "serrano". Y Manuel Castillo Ochoa, (enero 2016), -entre bromas, gracias y risas- en conversaciones sobre el tema, me decía: esta investigación la puedes realizar tú ("que eres marrón”), pero no lo podríamos realizar nosotros con este color ("que es blanco"). pensamiento y de nuestros actos se encuentra presente en gran parte de nuestra cotidianidad. La subjetividad está cargada con más de quinientos años de opresión que la escuela desde sus principales actores sociales, la resumen y la interpelan. Referimos al poder político dominante hasta el poblador del sentido común. Imaginemos el poder económico. Pero, precisamente, hay que entender el sentido de dominación que ella tiene. El poder busca, inculcar sometimiento y supeditación en sujetos sociales con grandes desigualdades sociales pero que se arrogan su predominio y su fuerza desde una intersubjetividad racializada. No se guardan sus temores, sus miedos y sus dudas. La violencia intersubjetiva racial y racista desde la colonialidad del discurso, de las narrativas y de nuestro léxico no se atiene a su negación, está presente y es obra de fuerzas estructurales que han transmitido su jerarquía para pensarnos en su distinción y en sus hechos. Aníbal Quijano (1992) logró el punto inicial de toda una racionalidad que las ciencias sociales no querían abrir. El racismo, no tiene color pero tiene firmas y tiene orígenes discursivos: en el hogar, en las colas, en el tránsito urbano, entre los papás, en la iglesia y, por último lo ubicamos y la orientamos en la escuela. Sin embargo, entendamos a este autor: "La subjetividad individual diferenciada es real; pero no existe sólo ante sí o por si. Existe como parte diferenciada, más no separada de una intersubjetividad. Todo discurso, o toda reflexión, individual, remite a una estructura de intersubjetividad. Está constituida en ella y ante ella. El conocimiento, en esta perspectiva, es una relación intersubjetiva a propósito de algo, no una relación entre una subjetividad aislada, constituida en si y ante sí, y ese algo". (Quijano, 1992: 14). En síntesis, describimos:

Primero: La escuela, en su mayoría la observan como el, "Lugar donde adquirimos conocimientos y los valores fundamentales del ser humano". Es decir, se trata de ubicar a la escuela como el espacio propicio que "libera al individuo" y que forja "progreso". Según sus definiciones. En el fondo, si bien los entrevistados con preguntas abiertas, nos correspondían que en la escuela existe una falta de respeto y una pérdida de valores entre sus miembros, en la parte numérica encontramos que la mayoría de ellos, responde al revés: que la escuela genera respeto y valores entre todos los actores sociales que la conforman. Como se ve, tenemos dos explicaciones, que pueden ser contradictorias, pero que en el fondo son parte complementaria de un mundo que se mueve 
en las dos formas de convivencia, en éstos ámbitos. Lo que se trata de analizar, es la pérdida de noción de escuela donde el respeto, el conocimiento y los valores pierden su prestancia.

Segundo: No son tan pocas las palabras que se encuentran en el vocabulario de los pobladores de la región y estas se complementan cuando explican las frases que conjugan dentro de estas expresiones discriminatorias: "No sirves para nada". "Eres un serrano", "Eres un shuco". "Cholo apestoso". "Indio cochino". "Cholo de mierda". "Cholo cochino". "Serrano asqueroso". Los maestros cuando se les hacía las preguntas con el temario a la mano, muchas de las palabras y las frases la describían dentro de un jolgorio que muchas veces terminaban dando cuenta de un hecho que les incluía en su forma discriminatoria en la que también se veían participantes. De igual modo, las cifras demuestran que es muy común escuchar las palabras racistas entre alumnos. Lo que concuerda con todas las denominaciones que se han realizado al respecto. Y aquí, lo primero, que sale a relucir es la palabra "cholo". Pero hay que tener cuidado porque estamos con profesores de la sierra huanuqueña donde, los indicios testimoniales ponían el sujeto "cholo" como el sentido de lo serrano o de lo andino, por lo que no nos puede preocupar la noción de "serrano e indio" rezagada en total. Más bien, lo que se hace sinónimo de todo ello es la palabra "shuco" cuya definición, es más agresiva e intolerante, sobre todo cuando se trata de pobladores "recién bajados" de las partes altas de Huánuco. Sin embargo, cuando la pregunta comienza a especificarse y se habla de discriminación bajo alternativas estructuradas, sale a relucir la palabra "serrano" y "cholo" como acepciones de discriminación. Esto quiere decir que las palabras siguen en la cabeza con mayor fuerza y como sentido común de una población que lo lleva perenemente.

Tercero: El significado de la palabra "cholo" se asocia como "Humillación para el poblador de la sierra", y "Ser peruano y lo mejor del país", en lo cuantitativo. Algo contradictorio por cuanto, se mezclan las dos partes que implican, su discriminación pero a la vez su elevada autoestima. Estas respuestas no entran en relación con las versiones testimoniales de los maestros donde lo indican como una palabra muy estigmatizada por parte de los estudiantes. Esto es, contrario a lo cholo, que se refiere como, El color mestizo de la sierra, que no cobra tanta importancia en términos numéricos.
De igual forma sucede con las expresiones "cholo de $\mathrm{m}$...", la cual se responde que es una frase "despectiva y racista" para una gran mayoría de los encuestados; pero que es muy "común en la calle" y que es expresión de "criollos o blancos" en un segundo momento. Esto nos hace deducir que el desprecio más que social es racial y cobra extensión en ámbitos públicos.

\section{Referencias bibliográficas}

Ansion, Juan y Madeleine ZúNIIGA (1997). Interculturalidad y educación en el Perú. Lima: Foro Educativo.

Aquézolo, Manuel (Compilador). (1976). La polémica del indigenismo. José Carlos Mariátegui / Luis Alberto Sánchez. Lima: Mosca Azul, editores.

Ardito, Wilfredo (2009). Reflexiones peruanas. Por un país sin discriminación. Lima: Coordinadora Nacional de Derechos Humanos.

Bourdieu, Pierre y Loïc Wacquant (1995). Respuestas. Por una antropología reflexiva. Barcelona: Anagrama.

Bruce, Jorge (2007). Nos habiamos choleado tanto. Psicoanálisis y racismo. Lima, USMP.

Callirgos, Juan Carlos (1993). El racismo: la cuestión del otro (y de uno). Lima: DESCO.

Castoriadis, Cornelius (1989). La institución imaginaria de la sociedad 2. Barcelona. Edit. Tusquets.

Contreras, Carlos y Patricia Oliart (2014). Modernidad y educación en el Perú. Lima: Minedu. Fondo Editorial.

Degregori, C.I. (s/f). Ocaso y replanteamiento de la discusión del problema indígena (1930-1977). En Centro Latinoamericano de Trabajo Social (editor). Indigenismo, clases sociales y problema nacional. Lima.

Degregori, C.I. (2013). Del mito del Inkarri al mito del progreso. Migración y cambios culturales. Obras Escogidas III. Lima: IEP.

De la Cadena, Marisol (2007). "Introducción”. En: De la Cadena, Marisol (ed.) Formaciones de indianidad. Articulaciones raciales, mestizaje y nación en América Latina. Popayán: Envión.

De la Cadena, Marisol (2004). Indígenas mestizos. Raza y cultura en el Cuzco. Lima: IEP.

Domínguez Condezo, Víctor. Heroica resistencia de la cultura andina. Deslindes sobre la educación y la cultura. Huánuco: Universidad de Huánuco.

Espinoza, Oscar y Luisa Belaunde (2014). ¿Indigenismos, ciudadanias? Nuevas miradas. Lima: Minedu. Fondo Editorial.

Flores Galindo, Alberto (1988). Buscando un Inca. Iden- 
tidad y utopia en los andes. Lima: SUR. Casa del Socialismo.

Golte, Jürgen (1980). Gregorio Condori Mamani o la bancarrota del sistema cognitivo andino. En: La Revista No. 3. Noviembre. pp.18-20. Lima: IEP.

Golte, Jürgen (1981). ¿Qué es la cultura frente a la historia? En: La Revista No. 4. Abril. pp. 59-63. Lima: IEP.

Jacinto, Pedro (2016). Discriminación racial y racista en la educación peruana. En: Investigaciones Sociales No 36, Vol. 20. Lima: Revista del IIHS- UNMSM. Enero-Junio.

JaCinto, Pedro (2014). Sobre la subjetividad racial y racista en la educación peruana. En: Yuyaykusun No 7 Noviembre. Lima: URP, Departamento de Humanidades.

JACINTO,Pedro (2011). La colonialidad del imaginario racial y racista en la educación peruana. En: Scientia No 12, Vol. 12, Lima: CIURP.

Levi-Strauss (1974). Raza e historia. New York: Unesco.

Lorente, Sebastián (?/1855). Pensamientos sobre el Perú. Lima. UNMSM. Departamento de Publicaciones. (Nota preliminar de Alberto Tauro). pp. 86.

ManRiQue, Nelson (1999). La piel y la pluma: escritos sobre literatura, etnicidad y racismo. Lima: SUR. Casa de estudios del Socialismo.

Mariátegui, J.C. (1972). Peruanicemos al Perú. Lima: Edit. Amauta.

Méndez, Cecilia (2010). De indio a serrano: nociones de raza y geografía en el Perú. (Siglo XVIII al XXI). En: Rev. Histórica. Lima: PUC.

Mejía Navarrete, Julio (2016). América Latina, modernidad y conocimiento. Lima: Fondo Editorial, Facultad de Ciencias Sociales,UNMSM.

Montoya, Rodrigo (1987). La cultura quechua hoy. Lima: Hueso Húmero Editores.

Montoya, Rodrigo (1990). Por una educación bilingüe en el Perú. Lima: Mosca Azul Edit. / CEPES.

Montoya, Rodrigo (2011). El porvenir de la cultura. Lima: UNMSM / Instituto Nacional de Cultura, Cusco.

Nugent, Guillermo (2014). El laberinto de la choledad. Páginas para entender la desigualdad. Lima: UPC. Fondo Editorial.

Oboler, Suzanne, (1996). El mundo es racista y ajeno: Orgullo y prejuicio en la sociedad limeña contemporánea. Lima: IEP, Documento de trabajo No 74.
Oboler, Suzanne y Juan Carlos Callirgos (2015). El racismo peruano. Lima: Ministerio de Cultura/ IEP.

Ortiz Rescanierre, Alejandro (1999). El racismo ilustrado o cuando se ve lo propio con ojos ajenos. En: Revista Anthropologica No 17, Vol. 17. Lima: PUCP.

Palma, Clemente (1897). El porvenir de las razas. Tesis de bachillerato en la Facultad de Filosofía y Letras de la UNMSM.

Piscoya, Luis (2002). Cuánto saben los maestros. Lima: Fondo Editorial. UNMSM.

Planas, María Elena y Néstor Valdivia (2009). Discriminación y racismo en el Perú: un estudio sobre modalidades, motivos y lugares de discriminación en Lima y Cusco. Mimeo. Lima: GRADE/ UPCH.

Portocarrero, Gonzalo (2013). La utopia del blanqueamiento y la lucha por el mestizaje. Buenos Aires: CLACSO.

Portocarrero, Gonzalo y P. Oliart (1989). El Perú desde la escuela. Lima: IAA.

Quijano, Aníbal (1980). Dominación y cultura. Lo cholo y el conflicto cultural en el Perú. Lima: Mosca Azul Edit.

Quijano, Aníbal (1992). Colonialidad y modernidad / Racionalidad. En: Perú Indígena Vol.13. No.29. pp.11-20. Lima: IIP.

Quijano, Aníbal (1993). Raza, etnia y nación en Mariátegui. En: José Carlos Mariátegui y Europa. El otro aspecto del descubrimiento. Lima: Editora Amauta. pp. 167-189.

Quijano, Aníbal (1994). Colonialidad del poder y democracia en América Latina. En: Debate No. 77. Marzo-Mayo. Lima: Apoyo.

RochabRÚN, Guillermo ( 2014). Una vana pretensión: ser racista en el Perú. En: Rochabrún, Drinot y Manrique: $R a-$ cismo, ¡sólo un juego de palabras? Lima: IEP/Ministerio de Cultura.

Rubio Fatacciolli, Alberto (1990). Sebastián Lorente y la educación en el Perú del siglo XIX. Prologado por Carlos Daniel Valcárcel. Lima: Editorial Allamanda.

Segato, Rita Laura (2010). Los cauces profundos de la raza latinoamericana: una relectura del mestizaje. En: Critica y Emancipación, (3): 11-44.

Valdivia, Néstor (2009). ¿ ¿Somos o no racistas los peruanos? Algunas evidencias desde las Ciencias Sociales. En: Le Monde Diplomatique. Lima: Dossier, Año II, Número 24, Abril. 